\title{
From basin to sub-basin scale assessment and intercomparison of numerical simulations in the Western Mediterranean Sea
}

\author{
Mélanie Juza ${ }^{\mathrm{a}, 1}$, Baptiste Mourre ${ }^{\mathrm{a}}$, Jean-Michel Lellouche ${ }^{\mathrm{b}}$, Marina Tonani ${ }^{\mathrm{c}}$, and Joaquin \\ Tintoré ${ }^{\mathrm{a}, \mathrm{d}}$ \\ ${ }^{a}$ SOCIB, Parc Bit, Naorte, Bloc A $2^{\circ} 3 p, 07121$ Palma de Mallorca, Spain \\ ${ }^{b}$ Mercator Océan, Parc Technologique du Canal, 8-10 rue Hermès, 31520 Ramonville Saint-Agne, \\ France \\ ${ }^{c}$ Istituto Nazionale di Geofisica e Vulcanologia, Via Donato Creti 12, 40128 Bologna, Italy \\ ${ }^{d}$ IMEDEA (UIB-CSIC), calle Miquel Marquès 21, 07190 Esporles, Islas Baleares, Spain
}

\begin{abstract}
This study describes a quantitative evaluation of simulations in the western Mediterranean Sea at basin and sub-basin scales. The Mediterranean Forecasting System and the Mercator-Océan simulations provide operational ocean forecasts and hindcasts in the Mediterranean, and are also used as initial and boundary conditions for regional models. In this context, hindcast simulations from 2009 to 2012 are compared with available multi-platform observations at various spatial and temporal scales to evaluate their performance. Both simulations reproduce well the observed mean conditions and variability over the last years. The sub-basin scale analyses of the three-dimensional ocean structures and water mass properties reveal seasonal and regional temperature and salinity errors at the surface in both simulations, as well as significant biases at intermediate and deep layers in the Mediterranean Forecasting System. The simulated surface geostrophic velocities are weaker than those derived from altimetry, and circulation biases persist in the Balearic Sea. Additionally, the seasonal existence of the Alboran gyres is not well reproduced in either simulation. The identification of regional simulation biases is essential to advance from global to regional and local scale forecasting, in particular, improving the representation of the local physical processes and their interactions with the sub-basin dynamics and the general circulation.
\end{abstract}

Key words: numerical simulations; sub-basin scale assessment; western Mediterranean Sea; multiplatform and multi-scale observations; Mediterranean Forecasting System; Mercator-Océan

${ }^{1}$ Corresponding author. SOCIB, Parc Bit, Naorte, Bloc A $2^{\circ}$ 3p, 07121 Palma de Mallorca, Spain. Tel.: +34 9714399 98. Email address: mjuza@ socib.es (M. Juza). 


\section{Introduction}

The Mediterranean Sea is a particularly interesting oceanic basin for climatic, environmental and physical studies since most of the ocean physical processes found throughout the world ocean occur in this basin (Malanotte-Rizzoli et al., 2014). These processes play an important role in governing marine sub-systems dynamics (biology, acoustics, and sedimentology). The Mediterranean Sea circulation is composed of three predominant and interacting spatial scales: basin scale (including the thermohaline circulation), sub-basin scale and mesoscale. Its complexity is now well established because of the wide range of spatio-temporal variability scales and their interaction, forming a highly variable general circulation (Robinson et al., 2001).

Despite the increasing amount of available ocean observations over the last decades, which has greatly enhanced our knowledge about the ocean state, variability and dynamics, these observations remain limited in time and space. The satellite-derived products are restricted to the surface and the coverage of in situ observations is generally sparse. In this context, ocean numerical simulations provide a complementary source of information, which is very useful to better understand the complexity of ocean dynamics at various spatial and temporal scales. In the Mediterranean Sea, the internal Rossby radius of deformation is $0(10-15 \mathrm{~km})$, which is four times smaller than typical values of the world ocean (Robinson et al., 2001). Therefore, the study of the ocean system requires high resolution in both observations and ocean models. The increase of computer power and the progress in numerical techniques over the last decades have led to an increase of the spatial resolution of ocean models, enabling them to represent or resolve the mesoscale dynamics, and thus be potentially more realistic. High resolution modelling representing realistic ocean variability at various spatial and temporal scales is a challenge for both the ocean modelling and the operational oceanography communities in the coming years.

Comparisons of numerical simulations with multi-platform observations are necessary to assess the performance of the simulations and to evaluate their capacity to reproduce observed ocean features at various temporal and spatial scales. These comparisons are also used to quantify the possible simulation biases and attempt to determine their origins. This in turn allows to improve the hindcast and forecast simulations, to study and better understand ocean physical processes in well simulated regions and to better address ocean variability analyses at interannual and longer time scales. Several studies have compared simulations in the Mediterranean Sea with observations investigating the mesoscale, the seasonal and interannual variability of the surface circulation using altimetry (Bouffard et al., 2008; Vidal-Vijande et al., 2011; Pascual et al., 2014), the basin scale (the whole Mediterranean, western and eastern parts) interannual variability (Demirov and Pinardi, 2002; Adani et al., 2011; Vidal-Vijande et al., 2011; Pinardi et al., 2013), or major physical processes impacting on the general circulation such as water mass formation and exchanges (Hermann et al., 2010; Ben Ismail et al., 2012; Juza et al., 2013), and the mesoscale dynamics (Bouffard et al., 2012; Guihou et al., 2013).

In the framework of the European MyOcean project (http://www.myocean.eu), the Mediterranean Forecasting System (MFS) (Tonani et al., 2008, 2014) and Mercator-Océan (Lellouche et al., 2013) are the two current operational systems covering the whole Mediterranean Sea. Both forecast and hindcast numerical simulations of the two systems are available and provide initial and/or lateral boundary conditions for higher resolution regional models which are required to study regional and coastal dynamics and to enhance our understanding of the ocean dynamics. High resolution regional models are also necessary to better represent the wide range of spatio- 
temporal ocean variability, including the mesoscale which is essential for operational applications (e.g. search and rescue, fishery management, oil spill response). Most of regional operational models in the Mediterranean Sea are nested into MFS such as the Adriatic Forecasting System (Oddo et al., 2005), the Sicily Channel Regional Model (Olita et al., 2012), the Tyrrhenian Sea Forecasting (Vetrano et al., 2010), the Aegean-Levantine Forecast System (Korres and Lascaratos, 2003) or the Western Mediterranean OPerational forecasting system (Juza et al., 2015). Mercator is also used to force regional models at the boundary such as the Iberian Biscay Irish regional system (Cailleau et al., 2012). Both Mercator and MFS have been progressively improved through quantitative comparisons of forecasts and hindcasts with observations and sensitivity tests (Oddo et al., 2009; Tonani et al., 2009; Adani et al., 2011; Lellouche et al., 2013). Nevertheless, most of assessments of simulations in the Mediterranean Sea are based on basin scale features and metrics (Oddo et al., 2009; Tonani et al., 2009; Vidal-Vijande et al., 2011) partially because of the lack of data at sub-basin scale. Regional quantitative assessments are now possible with the substantial increase of observational data, and are needed to detect regional biases and to improve the local physical processes, the sub-basin scale dynamics and the general circulation.

In this study, a regional and multi-scale assessment approach is proposed. The hindcast MFS and Mercator simulations are evaluated and quantitatively compared at sub-basin scale with available multi-platform observations (in situ measurements and satellite products) over the recent 2009-2012 period, during which new observations (such as glider data) and products have been made available. Statistical diagnostics have been developed to assess and inter-compare the simulations at various spatial and temporal scales, in different dynamical regions and in key sections. The assessment focuses on the Western MEDiterranean Sea (WMED) which in this study extends from the Strait of Gibraltar to the Corsica-Sardinia Islands at $9^{\circ} \mathrm{E}$ (Fig. 1). The assessment will address the ocean surface features and their temporal variability as well as the vertical ocean structure from basin to sub-basin scales. Additionally, as water mass formation and exchanges have a dynamical impact on the ocean stratification and circulation, simulated water mass characteristics are also examined in formation areas and at "choke points" of the WMED.

The paper is organized as follows. An overview of the study area is first given in Section 2. Section 3 introduces the numerical simulations which are assessed in this study. The methodology, based on multi-platform observations and multi-scale assessment, is described in Section 4. In Section 5, the simulations are evaluated in terms of temporal mean conditions, circulation and variability at basin scale. Section 6 extends the assessment to sub-basin and local scales investigating regional variability and ocean processes. Finally, conclusions are given in Section 7.

\section{Western Mediterranean Sea overview}

\subsection{General surface circulation}

The Atlantic Jet (AJ) enters the Alboran Sea through the Strait of Gibraltar bringing Atlantic Water (AW) into the Mediterranean Sea (Viúdez et al., 1998). The AJ, flowing with a velocity of $\sim 1 \mathrm{~m} / \mathrm{s}$, feeds the quasi-permanent Western Alboran Gyre (WAG) and drives the circulation in the Alboran Sea (Baldacci et al., 2001). The AJ meanders eastwards and forms also the intermittent Eastern Alboran Gyre (EAG) in the eastern part of the Alboran basin (Tintoré et al., 1988). The eastern boundary of the EAG is defined by the Almeria-Oran front. Farther east, the AW flows eastwards, 
forming the Algerian Current, along the North African coast until crossing the Sardinia Channel $\left(8.5^{\circ} \mathrm{E}\right)$ (Millot, 1999).

In the northern part of the WMED, the northward currents along each side of Corsica join and form the Northern Current (NC) in the Ligurian Sea (Millot, 1999). This permanent current flows southwestwards along the French and Spanish coast. In the Balearic Sea, the NC flows through the Ibiza Channel or retroflects cyclonically over the northern slopes of the Balearic Islands to form the quasi-permanent Balearic Current (BC) (Pinot et al., 1995). The Catalan and Balearic fronts separate the $\mathrm{NC}$ and the $\mathrm{BC}$, respectively, from the old $\mathrm{AW}$ in the center of the Balearic Sea (Font et al., 1988). The ocean dynamics in the Balearic Sea is particularly complex and variable. The bathymetry may increase the (sub-)mesoscale activity (e.g. eddies, filaments and shelf-slope flow modifications) affecting the meridional water mass exchanges between the north-western (Gulf of Lion) and the south-western (Algerian Sea) Mediterranean through the Balearic Channels (Astraldi et al., 1999; Pinot et al., 2002).

\subsection{Water mass characteristics}

The WMED is a four-layer system with water masses originating from the Atlantic Ocean and the eastern Mediterranean Sea or formed in the northern WMED. The AW gets into the Alboran Sea at the surface. Farther east, it is advected eastwards by the Algerian Current along the North African coast. After having recirculated in the eastern Mediterranean Sea where it became saltier through air-sea interaction and mixing processes (Millot, 1999), the AW comes back into the WMED partly through the Tyrrhenian Sea and the Corsica Channel. Below the surface layer, the Levantine Intermediate Water (LIW), formed in the eastern Mediterranean Sea by convection of AW, enters the WMED through the Sicily Strait, probably mixed with the Cretan Intermediate Water (Millot, 2013). The LIW is characterized by temperature and salinity maxima (14-13.2 ${ }^{\circ} \mathrm{C}$ and $38.7-38.5$, respectively) generally found around 300-400m depth (Astraldi at al., 1999; Millot, 1999).

Two water masses are formed in the northern WMED. Winter Intermediate Water (WIW) is formed under severe winter conditions, predominantly along the continental shelf in the Gulf of Lion and the Balearic Sea (despite the influence of low salinities of continental origin) through winter convection of AW (Millot, 1999; Pinot and Ganachaud, 1999). The WIW is identifiable by a minimum of temperature in the intermediate layer between the AW in the surface and the denser LIW. Under severe winter conditions, the Gulf of Lion is also a place where deep convection and formation of Western Mediterranean Deep Water (WMDW) may occur. The WMDW occupies the deep layer, generally below $1500 \mathrm{~m}$ depth (Millot and Taupier-Letage, 2005).

\section{Numerical simulations}

As part of the MyOcean project, two ocean forecasting systems (MFS and Mercator) are currently producing daily forecasts over the whole Mediterranean Sea. Both forecast and hindcast simulations can be used as initial and boundary conditions for regional models. In this section, the available MFS and Mercator hindcast simulations with data assimilation, which are evaluated in this study, are described.

\subsection{Mediterranean Forecasting System}


The MFS simulation (version myov04; Tonani et al., 2008, 2014) is based on the NEMO-OPA code (Nucleus for European Modelling of the Ocean), version 3.2 (Madec et al., 2008). MFS covers the entire Mediterranean Sea and also extends into the Atlantic (until $18^{\circ} \mathrm{W}$ ) to better resolve the exchanges of water masses between the Atlantic Ocean and the Mediterranean Sea at the Strait of Gibraltar (Oddo et al., 2009). The simulation has a horizontal resolution of $1 / 16^{\circ} \times 1 / 16^{\circ}$ and 72 unevenly spaced vertical z-levels (Tonani et al., 2008; Oddo et al., 2009). It is initialized in January 1985 by a temperature and salinity monthly climatology from the SeaDataNet project (http://www.seadatanet.org). In the Atlantic, it is nested into the monthly mean climatological fields of $1 / 4^{\circ} \times 1 / 4^{\circ}$ Mercator global model (Drevillon et al., 2008). The ERAinterim reanalysis fields from the European Centre for Medium-range Weather Forecasts (ECMWF), with a $0.75^{\circ}$ spatial resolution and 6-hourly temporal resolution, are used to force the simulation using bulk formulae to compute momentum, water and heat fluxes (Tonani et al., 2008). Monthly mean data sets are used for river runoffs and precipitations (Oddo et al., 2009). Data assimilation is implemented in the system using a variational data assimilation scheme (Dobricic and Pinardi, 2008) for temperature and salinity vertical profiles and satellite sea level anomaly along track data (MyOcean, SL-TAC). Sea surface temperature products (MyOcean, OSI-TAC) are also used to correct the heat fluxes at the air-sea interface (Marullo et al., 2007; Buongiorno Nardelli et al., 2013). The model outputs are daily means of three-dimensional temperature, salinity, and horizontal velocity fields, and of sea surface height.

\subsection{Mercator-Océan simulation}

The Mercator PSY2V4R4 simulation (Lellouche et al., 2013) is also based on the NEMO-OPA code, version 3.1 (Madec et al., 2008). This simulation covers the Atlantic Ocean (between $20^{\circ} \mathrm{S}$ and $81^{\circ} \mathrm{N}$ ) and the Mediterranean Sea with a spatial horizontal resolution of $1 / 12^{\circ} \times 1 / 12^{\circ}$, varying with the cosine of the latitude, and 50 unevenly spaced vertical z-levels. At the latitude of the Mediterranean Sea, horizontal resolutions of MFS and Mercator are practically equivalent. The simulation is initialized in October 2006 by the monthly temperature and salinity Levitus 2005 climatology. The 3-hourly ECMWF operational atmospheric fields force the simulation using the bulk CORE formulae (Large and Yeager, 2009). The river runoffs applied to the system are the Dai and Trenberth (2002) monthly climatology. Sea surface temperature (Reynolds AVHRR 1/4 ${ }^{\circ}$ ), along track sea level anomaly and in situ temperature and salinity vertical profiles are assimilated using the Mercator assimilation scheme (Tranchant et al., 2005; Lellouche et al., 2013). Lastly, the model outputs are daily means of three-dimensional temperature, salinity, and horizontal velocity fields, and of sea surface height.

\section{Methodology}

\subsection{Multi-platform observations}

Three types of observational datasets, from satellite products and in situ measurements, covering the period 2009-2012 are used for comparison with the simulations:

(1) Daily maps of sea surface temperature (SST) over the Mediterranean Sea, provided by CNRISAC (MyOcean, OSI-TAC) and distributed by MyOcean, are used to assess the SST patterns in the simulations. The data are obtained from infra-red measurements collected by satellite radiometers 
and optimally interpolated on a regular grid with a $1 / 16^{\circ}$ spatial resolution (Buongiorno Nardelli et al., 2013).

(2) Delayed-time mapped absolute dynamic topography and associated geostrophic velocities from altimeter missions are used to evaluate the general surface circulation and the mesoscale variability. These data have been interpolated on a regular $1 / 8^{\circ} \times 1 / 8^{\circ}$ grid and computed with a daily temporal resolution. These products are derived combining all available satellites (up to four satellites at given time). This dataset has been provided by AVISO-CLS SSALTO/DUACS (2014).

(3) Quality controlled in situ temperature and salinity profiles collected worldwide using various instruments and compiled in the ENACT-ENSEMBLES EN4.0.2 database (Good et al., 2013) are used to assess the hydrographic properties in depth and the representation of water masses. Hydrographic data with different spatial and temporal sampling characteristics both in terms of coverage and resolution are available. These data come from expandable bathythermographs (XBTs), Argo floats and CTD transects including dense glider sections, especially in the Gulf of Lion and the Liguro-Provencal basin. All data not flagged as "good" have been rejected. Fig. 1 displays the position of in situ hydrographic profiles used in this study. Additionally, a glider mission operated by the Balearic Islands Coastal Observing and Forecasting System (SOCIB) in the Ibiza Channel in March-April 2011 (three back-and-forth transects during two weeks) (Heslop et al., 2012; Tintoré et al., 2013) is also considered in this study (Fig. 1). These high-resolution data will be used to accurately characterize and evaluate the water mass properties in the Ibiza Channel, which is a key section since it is the place of water mass exchanges between the northern and the southern parts of the WMED.

Some of these observations have been assimilated in the simulations, such as data from Argo floats and XBTs, and remote sensing observations. The high resolution glider observations have not been assimilated in the simulations, thus providing an independent assessment.

\subsection{Data processing and assessment protocol}

As the Boussinesq approximation is applied to the model equations, conserving the volume and varying the mass, the simulations do not properly represent the steric effect of the sea level (Greatbatch, 1994). For this reason, the steric effect has been computed as the vertical integration, from the surface to the bottom, of the specific volume anomaly (respect to the specific volume at 35 psu and $0^{\circ} \mathrm{C}$ ) and added to the sea level in the simulation before its comparison with observations.

The outputs of the simulations are interpolated at the observed space-time positions for their assessment and intercomparison. At basin scale, temporal mean conditions, circulation and variability over the WMED are investigated through statistical metrics (temporal mean, standard deviation, mean error (ME) and root mean square difference (RMSD), see definition in the Appendix). At sub-basin scale, regional, seasonal and interannual variability of the surface and deep oceans are analysed. The regions with typical sub-basin dynamics in the $0-200 \mathrm{~m}$ upper layer have been defined by Manca et al. (2004) (Fig. 1) according to the schematic representation of the upper thermohaline circulation in the WMED (Millot, 1999). Additionally, characteristic ocean processes (mesoscale features and water masses) of the WMED are investigated at regional and local scales.

\section{Mean conditions and variability at basin scale}


In this section, the simulations are first evaluated and compared with observations in terms of mean sea surface features and hydrographic properties at basin scale.

\subsection{Sea surface temperature}

The temporal mean and variability of the SST over the period 2009-2012 are first examined to assess the large-scale features and differences between observations and simulations (Fig. 2 and 3). The mean observed SST (Fig. 2a) shows that the northern part of the WMED has the coolest waters throughout the period, with a minimum of $16.4^{\circ} \mathrm{C}$ in the Gulf of Lion due to the cooling effect of frequent northerly Mistral and northwesterly Tramontane winds (Estournel et al., 2003). The highest mean values of observed SST are reached around the Balearic Islands and in the Algerian basin with a maximum of $20.1^{\circ} \mathrm{C}$. The Balearic Sea experiences the largest temperature range over the annual cycle (López García and Camarasa Belmonte, 2011). As shown in Fig. 2b, the maximum of variability is found in this region with a standard deviation reaching $5^{\circ} \mathrm{C}$ while the minima are located in the Alboran Sea and the Gulf of Lion with standard deviations of 2.5 and $3.5^{\circ} \mathrm{C}$, respectively.

The MFS and Mercator simulations reproduce reasonably well the spatial structure of SST temporal mean and variability over the analysis period (Fig. 2c,d,e,f). Although SST data are assimilated in both simulations, persistent differences with satellite products are highlighted (Fig. 3a,b,c,d). In the coastal Gulf of Lion, MFS and Mercator are colder than satellite products with ME of 0.8 and $0.7^{\circ} \mathrm{C}$, respectively, and RMSD higher than $1^{\circ} \mathrm{C}\left(1.3\right.$ and $1.5^{\circ} \mathrm{C}$, respectively). In this region of strong air-sea interactions (Renault et al., 2012), the simulations errors could be due to the atmospheric forcing, wind and surface flux uncertainties. Additionally, the coastal area is subjected to strong river inputs (the Rhone); the differences between satellite products and simulations may also be explained by the climatological river runoffs applied to the simulations. The coastal areas are also the place of wind-induced upwelling/downwelling (Bakun and Agostini, 2001) that may be not well represented in satellite products and simulations. In the North Balearic frontal area, differences are found for the mean SST (especially in MFS where the ME reaches $0.4^{\circ} \mathrm{C}$ ) and its temporal variability (RMSD of 0.75 and $1{ }^{\circ} \mathrm{C}$ in MFS and Mercator, respectively), due to the difference in the position of the simulated temperature front. Farther south, in the Balearic Sea, which is a place of strong seasonal variability of SST, simulation errors are found, particularly in Mercator where the ME and RMSD reach 0.4 and $0.75^{\circ} \mathrm{C}$, respectively. Finally, in high mesoscale activity areas, such as the Alboran Sea and along the Algerian coast, differences are also found in terms of temporal mean and variability. The mislocation of mesoscale features can partially explain the simulation errors. In the Alboran Sea, the differences may also be due to the inflow intensity and orientation at Gibraltar or the mislocation of the confluence of recent and modified AWs.

\subsection{Surface circulation}

\subsubsection{Mean geostrophic currents}

The general surface circulation can be characterized and assessed through the temporal mean of geostrophic currents. Fig. 4a depicts the temporal mean of the geostrophic velocities derived from the altimetry over the period 2009-2012. In the Alboran Sea, the mean geostrophic velocity of the WAG from satellite products reaches $0.6 \mathrm{~m} / \mathrm{s}$, in agreement with previous studies (Millot, 1999; Renault et al., 2012). The EAG has a weaker mean velocity $(0.4 \mathrm{~m} / \mathrm{s})$ than the WAG because of its 
lower intensity and more variable existence. The mean simulated surface geostrophic currents, estimated from the simulated free surface, are shown in Fig. 4b,c. In both simulations, the WAG is well located but its mean velocity is weaker than the one derived from altimetry, especially in the Mercator simulation where the differences reach $0.3 \mathrm{~m} / \mathrm{s}$. The simulated EAG is also too weak in both MFS and Mercator with mean velocity up to 0.3 and $0.25 \mathrm{~m} / \mathrm{s}$, respectively.

Farther east, the Algerian Current, as depicted from altimetry, is stronger between $0^{\circ}$ and $2^{\circ} \mathrm{E}$ (with a mean value reaching $0.5 \mathrm{~m} / \mathrm{s})$ than in the eastern part $(0.25 \mathrm{~m} / \mathrm{s})$. In the western Algerian Current, strong differences between Mercator and the altimetry products are found reaching $0.2 \mathrm{~m} / \mathrm{s}$. The mean geostrophic velocities in both simulations are also weaker than in satellite products in the middle and eastern parts of the Algerian Current where the mean biases reach $0.05-0.1 \mathrm{~m} / \mathrm{s}$.

In the western Ligurian Sea, the NC derived from altimetry has a maximum around $0.35 \mathrm{~m} / \mathrm{s}$. In both simulations, the NC is weaker than in the satellite products. The differences of intensity with observations are around 0.1-0.2 and 0.05-0.1 m/s, in MFS and Mercator, respectively. Moreover, further analyses of monthly mean simulated currents have revealed a circulation bias of the western Corsica Current in Mercator (not shown). Although the mean simulated current over the analysis period is in good agreement with the observations, in some monthly occurrences, this current turns more westwards in Mercator than in the observations before joining the NC.

In the Balearic Sea, the observed and simulated mean circulations strongly differ. In particular, as already highlighted in Pinardi et al. (2013), the NC totally turns eastwards $2^{\circ} \mathrm{E}$ north of Mallorca Island in the MFS simulation. This ocean circulation bias is persistent during the whole period of study (not shown). The Mercator simulation better represents the general circulation in this area with simulated NC and BC quite realistically located. However, the Catalan and Balearic fronts are not as marked as in the observations, and mesoscale circulation biases are found, especially in the Balearic Channels. The complexity of the dynamics in this region (described in Section 2) makes the simulation of the regional ocean circulation and its spatio-temporal variability difficult. The possible origins of the ocean circulation simulation bias in the Balearic Sea are under investigation.

\subsubsection{Kinetic and eddy kinetic energies}

The kinetic energy (KE) and eddy kinetic energy (EKE) are computed as $1 / 2\left[U g^{2}+V g^{2}\right]$ and $1 / 2\left[U g^{2}+V g^{\prime 2}\right]$, respectively, where $U g$ and $V g$ are the zonal and meridional surface geostrophic currents, $U g^{\prime}$ and $V g^{\prime}$ the anomalies with respect to the temporal mean. While the KE represents the energy of the total surface geostrophic flow (mean and fluctuations), the EKE allows the identification of regions with high variability such as current meanders, eddies, or fronts. Fig. 5a,d show the mean geostrophic KE and EKE derived from altimetry over the analysis period. The highest energy and mesoscale activity are observed in the Alboran Sea, corresponding to the WAG and EAG, with a maximum of mean KE and mean EKE of around 0.21 and $0.04 \mathrm{~m}^{2} / \mathrm{s}^{2}$, respectively. High values of mean observed $\mathrm{KE}$ are also found in the western Algerian Current between $1^{\circ} \mathrm{W}$ and $1.5^{\circ} \mathrm{E}\left(0.1-0.15 \mathrm{~m}^{2} / \mathrm{s}^{2}\right)$. In the eastern part of Algerian Current, southwest of Sardinia, the mean value of observed KE is around 0.04-0.05 m/2/s while the mean EKE reaches $0.03 \mathrm{~m}^{2} / \mathrm{s}^{2}$. This is associated with the frequent formation of anticyclonic eddies. In the northern part of WMED, the high values of $\mathrm{KE}$ are associated with the $\mathrm{NC}$ flowing along the French coast and their mean value is around $0.04-0.07 \mathrm{~m}^{2} / \mathrm{s}^{2}$. Note that these results are in agreement both qualitatively and quantitatively with previous studies using altimetric products over a longer period (Pascual et al., 2014). 
The geostrophic KE and EKE have also been computed from the simulated surface geostrophic currents. Fig. 5b,c (5e,f) show the mean differences between the simulated and observed KE (EKE). The simulated KE is weaker in both MFS and Mercator than in satellite products. Highest differences with the altimetric products are found in the Alboran Sea, especially in the area associated with the WAG where the mean differences of KE (EKE) reach -0.16 (-0.02) and -0.17 ($0.02) \mathrm{m}^{2} / \mathrm{s}^{2}$ in MFS and Mercator, respectively. The mean KE averaged in the Alboran basin is around $0.06,0.04$ and $0.03 \mathrm{~m}^{2} / \mathrm{s}^{2}$ in the observations, MFS and Mercator, respectively. The mesoscale variability of the observed and simulated Alboran gyres is investigated more specifically in Subsection 6.2.1.

\subsection{Vertical hydrographic structure}

In situ vertical temperature $(\mathrm{T})$ and salinity $(\mathrm{S})$ profiles from Argo floats, XBTs and CTDs, the positions of which are displayed in Fig. 1, are used to complement the assessment to the vertical dimension and to characterize the three-dimensional hydrographic structure of the observed and simulated oceans. The medians of the distributions of $\mathrm{T}$ and $\mathrm{S}$ from observations and simulations, and of the associated misfits (simulated minus observed values) within 100-m layer bins have been computed. The $0-10 \mathrm{~m}$ upper layer has not been considered to eliminate the diurnal cycle effects, which are smoothed in the simulations by the daily mean computation. Moreover, most of data have been collected below $10 \mathrm{~m}$. In addition, the dense CTD transects from glider missions have been excluded to consider more homogeneous and random data from Argo floats and XBTs, to avoid introducing a statistical bias due to the very large number of glider data along specific sections and so to better estimate the regional simulation errors.

Fig. 6 shows the medians of the annual and climatological seasonal distributions of $\mathrm{T}$ and $\mathrm{S}$ misfits as a function of depth, estimated using all available profiles from Argo floats and XBTs of the WMED over the analysis period (Fig. 1). Although the depths of the thermocline and the halocline (150-200m) are well reproduced in both simulations (not shown), large T/S biases are found at the surface. The positive (negative) simulation median biases in $T(S)$ in the upper layer indicate that the simulations overestimate (underestimate) the heat (salt) content. Both MFS and Mercator are too warm especially in summer $\left(0.06\right.$ and $0.12^{\circ} \mathrm{C}$, respectively) and too fresh throughout the year (with median values up to -0.03 and -0.07 , respectively). Oddo et al. (2009) have suggested that the lower salinity found in the south WMED in MFS could be explained by an underestimation of the salinity of the inflowing AW. In the other regions, the ocean surface $\mathrm{T}$ and $\mathrm{S}$ biases can be explained by errors induced through atmospheric forcings and air-sea fluxes and/or by horizontal and vertical mixing processes. In the intermediate layer, cold biases are generally found in both MFS and Mercator with a maximum at $500 \mathrm{~m}$ (from -0.02 to -0.03 and $-0.07^{\circ} \mathrm{C}$, respectively), except for Mercator in 2009 and in wintertime. In the deeper layer (below $600 \mathrm{~m}$ ), persistent significant cold and salty median biases are found in MFS reaching $-0.1^{\circ} \mathrm{C}$ and 0.1 , respectively, while weaker biases are found in Mercator (warm bias $<0.03^{\circ} \mathrm{C}$ and very slight bias in salinity). Note that MFS assimilates the T/S profiles from Argo floats and XBTs only to $1000 \mathrm{~m}$ depth. Considering deeper data in the assimilation system might help to partially correct these biases. Additionally, in the intermediate and deeper layers, the simulation biases might be related to the vertical mixing parameterization. Investigating and improving this latter point might improve the simulations in the reproduction of water mass characteristics. 


\section{Sub-basin and local scale analyses}

376 This section extends the assessment from basin to sub-basin scale, analysing regional temporal

377 variability of surface features and hydrographic properties, as well as specific ocean processes.

\subsection{Regional evaluation}

\subsubsection{Sea surface temperature}

The monthly mean observed SST averaged over the WMED shows a clear seasonal cycle, which is well reproduced in both simulations, although warm biases are found in spring-summer especially in MFS (Fig. 7a). The annual cycles in the seven regions (cf. Fig. 1) are also well represented in MFS and Mercator (not shown). In accordance with the literature (López García and Camarasa Belmonte, 2011), the minimum values are recorded in February $\left(13.6-13.8^{\circ} \mathrm{C}\right.$ over the WMED, $12.8^{\circ} \mathrm{C}$ in Gulf of Lion) and the maximum in August $\left(24.7-25.7^{\circ} \mathrm{C}\right.$ in WMED, $27.1^{\circ} \mathrm{C}$ in the eastern Algerian). Additionally, the annual means and standard deviations of observed and simulated SST from 2009 to 2012 are shown in Fig. 7b,c for the seven regions. In the Gulf of Lion, the coldest annual mean of observed SST are found varying between 17.2 and $17.9^{\circ} \mathrm{C}$. Mercator is colder than the observations $\left(0.1-0.2^{\circ} \mathrm{C}\right)$ in 2009 and 2010 while MFS is warmer than the observations $\left(0.1^{\circ} \mathrm{C}\right)$ in 2011 and 2012. In the Liguro-Provencal and Algero-Provencal regions where the observed mean SST are $17.8-18.5^{\circ} \mathrm{C}$ and $18.8-19.3^{\circ} \mathrm{C}$, respectively, very weak simulation biases are found. In the Balearic Sea, the annual mean observed SST oscillates between 19.1 and $19.7^{\circ} \mathrm{C}$ over the period and warm biases are found in both simulations, in particular in Mercator in $2011\left(0.3^{\circ} \mathrm{C}\right)$. Warm biases are also found in the western and eastern Algerian basins, where the largest regional annual observed values are found $\left(19.4-19.9^{\circ} \mathrm{C}\right)$. In the Alboran Sea, warm biases are also found, especially in Mercator where the bias reaches $0.2^{\circ} \mathrm{C}$. The interannual evolution of the annual mean observed SST is well reproduced in both simulations. Moreover, the temporal variability is highly correlated in all regions except the Alboran Sea, with relatively warm 2009 and 2011 years, and colder 2010 and 2012. In the Alboran Sea, the observed and simulated mean SST increase from 2009 to 2011, and then decrease in 2012. Concerning the annual standard deviations of the regional observed and simulated SST (Fig. 7c), largest values are found in 2009 in all regions. In general, the simulated regional annual variability is weaker (larger) in Mercator (MFS) than in satellite products. However, the regional interannual variability is properly represented in both simulations in terms of amplitude and phase with correlations up to 0.9 in all regions (not shown).

\subsubsection{Vertical hydrographic properties}

The vertical structure of $\mathrm{T}$ and $\mathrm{S}$ simulation biases has also been investigated at sub-basin scale in the seven regions defined in Fig. 1 (not shown) as in Subsection 5.3. At the surface, the regional T and $\mathrm{S}$ simulation median biases are variable and depend on the season, the year and the simulation. As revealed partially in Subsection 5.1, by comparing simulated mean SST with satellite products, superficial warm biases are found in the Balearic Sea during the whole period. In the Gulf of Lion, cold median errors of $-0.03^{\circ} \mathrm{C}$ in both simulations are found in winter-spring. In the Alboran Sea, the superficial temperature median differences are seasonal: warm in winter-spring (higher than $\left.0.1^{\circ} \mathrm{C}\right)$, cold in summer-autumn $\left(-0.02^{\circ} \mathrm{C}\right)$. Concerning the salinity in the upper layer, fresh biases 
are found in both simulations in all regions as in WMED with strongest median biases reaching -0.3 (in 2012 and in autumn) in the Alboran Sea and around -0.15 in the western Algerian. In the intermediate and deep layers, the general findings on the simulation median $\mathrm{T}$ and $\mathrm{S}$ biases over the whole WMED (Subsection 5.3) are consistent over all regions with the same order of magnitude.

\subsection{Ocean processes}

\subsubsection{Alboran gyres}

As shown in Subsection 5.2.2, the Alboran Sea is the place of the highest energy and mesoscale activity in the WMED. The decomposition of the ocean signal in Empirical Orthogonal Functions (EOF) identifies and quantifies the spatial and temporal variability of the ocean field. The first and second modes of EOF analysis on observed and simulated sea level anomaly (SLA) over the period 2009-2012 are depicted in Fig. 8 together with the associated geostrophic currents. The first EOF (EOF1) of observed SLA represents $65.8 \%$ of the total variance, while the second EOF (EOF2) represents only $8.2 \%$. EOF1 is more characteristic of the EAG variability than the WAG variability. The temporal amplitude of EOF1 displays a clear annual periodicity. The first mode of SLA variability in the Alboran Sea is associated to the steric contribution of the seasonal cycle (Cazenave et al., 2002). An intensification (weakening) of the WAG and the EAG is observed during the spring-summer (winter-fall). EOF2 describes a WAG intensification (weakening), an EAG weakening (intensification) in opposite phase and the apparition of an anticyclonic (cyclonic) eddy at the eastern part of the Alboran Sea. EOF2 also highlights the well-defined Almeria-Oran front which separates the EAG and the cyclonic eddy east of EAG. No clear periodicity of the EOF2 temporal component is revealed since the associated variability is interannual (Renault et al., 2012; Pascual et al., 2014) and cannot be highlighted over our period of study.

The main observed modes of SLA variability are found in both simulations (Fig. 8). EOF1 represents a large part of the total variability with 65.2 and $60.9 \%$ in MFS and Mercator, respectively. Their associated temporal components depict the observed annual periodicity. They represent 71 and $83 \%$ of the observed EOF1 variability with a correlation of 0.65 and 0.91 , respectively. EOF2 is better reproduced in MFS than in Mercator in terms of both spatial pattern and temporal variability. The Almeria-Oran front is well reproduced and located in MFS. The associated temporal component represents $97 \%$ of the observed EOF2 variability and is relatively well correlated with the observations (0.7). The comparison with observations is more critical for Mercator. The spatial pattern of EOF2 in Mercator is completely different from the observed one (not shown). The EOF in Mercator that looks more like the observed EOF2 is the third EOF, depicted in Fig. 8. However, this mode represents only $4.9 \%$ of the total variability. While the WAG variability is not present in this EOF, the EAG, the eddy at the east and the associated Almeria-Oran front are weaker in Mercator than in observations and located further west. Finally, the associated temporal component displays a low correlation with the observations (0.37).

The EOF analysis in the Alboran Sea examines the Alboran gyres variability. However, it does not indicate their presence or persistence. To complete the study, the observed and simulated KE averaged in the WAG and EAG boxes have been computed. The boxes have been defined according to the position of WAG and EAG in the satellite products, MFS and Mercator, respectively. Fig. 9 shows the time series of the Alboran-, WAG- and EAG-box-averaged KE from observations and simulations. They have been low-filtered for clarity since the signal comprises very high temporal 
variability. A clear seasonal variability is observed over the Alboran Sea (Fig. 9a), with maxima (minima) reached in spring-summer (autumn-winter) around $0.07(0.03) \mathrm{m}^{2} / \mathrm{s}^{2}$, which is the signature of the WAG. Indeed, the correlation between the Alboran- and WAG-box-averaged observed KE time series (Fig. 9a,b) is around 0.9. The observed KE is stronger in the WAG than in the EAG (Fig. 9b,c), with temporal means over the period around 0.12 and $0.05 \mathrm{~m}^{2} / \mathrm{s}^{2}$, respectively. Generally, in accordance with Renault et al. (2012), more energy is found in the second half of the year for both gyres, with a quasi-persistence of WAG whereas EAG disappears in winter (replaced by a cyclonic eddy to the east).

Although MFS is more energetic than Mercator, neither time series of simulated Alboran-averaged KE represents the observed seasonal variability over the whole period. The WAG KE is weaker in the simulations than in satellite products with a temporal mean around 0.05 and $0.03 \mathrm{~m}^{2} / \mathrm{s}^{2}$ in MFS and Mercator, respectively. Moreover, MFS better represents the existence and variability of the WAG than Mercator. Fig. 9 depicts some KE maxima in MFS associated to observed maxima. In Mercator, the WAG KE is weak without clear seasonal periodicity and there is a no existence in 2011. The amplitude of the simulated EAG-averaged KE is better reproduced than in the WAG area. The temporal means in the EAG boxes are $0.05,0.05$ and $0.03 \mathrm{~m}^{2} / \mathrm{s}^{2}$ in the altimetry, MFS and Mercator, respectively. But, while the EAG in Mercator is not persistent as in the observations, the simulated EAG in MFS has a quasi-persistence.

\subsubsection{Water masses in key sections}

Observational data from gliders are here considered. These are independent data that have not been assimilated in MFS and Mercator. Very high-resolution hydrographic data have been collected along CTD sections in the WMED. Three key sections in different areas of the WMED in 2011 have been selected and examined to study the presence of water masses related to their recent formation and/or propagation.

As illustrated in Fig. 1, T and S data have been recorded along a dense CTD section in the western Ligurian Sea, in May-June 2011. The observed T/S diagram (Fig. 10a) shows the presence of the characteristic water masses of the WMED: the AW in the upper ocean layer with temperature greater than $13^{\circ} \mathrm{C}$, the LIW with its T and S maxima, and Deep Water (DW) in the bottom layer (> $800 \mathrm{~m}$ ). The simulated T/S diagrams (Fig. 10b,c) indicate that Mercator better reproduces the observed water masses in the Ligurian Sea than MFS. In the upper layer, T/S differences between observed and simulated AW are found with too much homogeneity in simulated $S$ values, especially in MFS. Additionally, as highlighted in Subsection 5.3, the simulated T is too cold in the intermediate layer in MFS. The T/S diagram confirms this bias and shows that MFS does not represent properly the T maxima associated with the observed LIW. The simulation median error is around $-0.14^{\circ} \mathrm{C}$ for this water mass in MFS. Mercator reproduces properly the LIW in the northeastern WMED.

Farther west, several glider transects have been performed in the Gulf of Lion in March-April 2011. The observed T/S diagram (Fig. 10d) highlights the presence of characteristic water masses of the northern WMED: the AW and LIW that have been advected westwards by the NC from the Ligurian Sea; the WIW and WMDW formed in the northern WMED in winter. The MFS and Mercator simulations reproduce the main water masses in the Gulf of Lion during the winter 2011 (Fig. 10e,f). However, T and S differences are found for the AW, especially in MFS with median values of $-0.03^{\circ} \mathrm{C}$ and 0.07 , respectively. Differences between simulations and observations are 
also highlighted in the T and S of WIW, particularly in MFS (median value around $-0.26^{\circ} \mathrm{C}$ and 0.14, respectively). Finally, errors in T maxima associated to the LIW persist in MFS. In the bottom layer $(>800 \mathrm{~m})$, WMDW is present in both simulations although $\mathrm{T} / \mathrm{S}$ median errors are found in MFS $\left(0.02^{\circ} \mathrm{C} / 0.1\right)$ and Mercator $\left(0.04^{\circ} \mathrm{C} / 0.01\right)$.

Farther south, in March-April 2011, the SOCIB glider has recorded dense transects in the Ibiza Channel at $39^{\circ} \mathrm{N}$. As highlighted by Heslop et al. (2012), Juza et al. (2013) and in Fig. 11a, the observed T/S diagram reveals the typical water masses of the WMED (AW, LIW, WMDW) and the presence of WIW in the Ibiza Channel at 50-200m (Fig. 11d). Juza et al. (2013) have shown, using a regional high-resolution simulation, that the main part of the WIW going through the Ibiza Channel during this period has been formed in the Ebro Delta region and has followed the southward NC. Fig. 11 shows that Mercator represents the presence of WIW in the Ibiza Channel, although $\mathrm{T} / \mathrm{S}$ biases are found $\left(0.2^{\circ} \mathrm{C} / 0.13\right)$. MFS has very strong surface $\mathrm{T} / \mathrm{S}$ biases $\left(0.69^{\circ} \mathrm{C} /-0.5\right)$ and does not reproduce the presence of WIW. This could be explained by the bias found in the general circulation in the Balearic Sea. As shown in Subsection 5.2.1, in MFS, the NC systematically deviates eastwards north of Mallorca Island and does not reach the southern subbasin. The Balearic Sea is a critical region for both simulations because of its complex dynamics and highly variable circulation.

\section{Discussion and conclusions}

The performance of available MFS and Mercator hindcast simulations with data assimilation in the western Mediterranean Sea has been investigated. In particular, a quantitative assessment of simulations at different scales, from basin to regional and local, has been carried out using an extensive multi-platform observational data set: sea surface temperature from satellite products, sea level anomaly and associated surface geostrophic currents derived from altimetry, temperature and salinity vertical profiles from expandable bathythermographs and Argo floats, as well as high resolution glider sections. The major findings are discussed first for the different scales and the main conclusions presented thereafter.

At basin scale, temporal mean conditions, circulation and variability have been analysed for the 2009-2012 period:

- The spatial structure of the temporal mean and variability of the simulated sea surface temperature is well represented over the study period. The major differences between the simulated and observed mean and variability have been found in the coastal Gulf of Lion, the Balearic Sea, the Alboran Sea, and along the North African coast.

- The simulated general surface circulation is also in good agreement with observations in the whole western Mediterranean Sea. However, the simulated mean surface geostrophic current and kinetic energy are weaker than those deduced from satellite products, especially in sub-basins characterized by significant and well defined quasi-permanent currents and mesoscale activity (Alboran, Algerian and Northern Currents). In addition, circulation errors associated with the western Corsica Current have been found in Mercator. Although this feature is masked by the temporal mean over the analysis period, this is a critical point since the simulation might be used as boundary conditions for higher resolution regional models in this area (e.g. WMOP, Juza et $a l .$, 2015). Moreover, significant errors persist in other sub-basins in MFS, in particular in a key transition sub-basin, the Balearic Sea. In this region, the ocean circulation acquires its 
complexity by the bathymetry, the northern wind driven and thermohaline forcings, the shelfslope exchanges, the strong mesoscale activity, the southern thermohaline forcing, and the water mass transport and exchanges between the northern and southern regions. The Balearic Sea remains a very challenging area for ocean modelling.

- Finally, the analyses of vertical hydrographic properties have shown median biases at basin scale. At the surface, persistent warm (during spring-summer) and fresh (throughout the year) biases have been found in both MFS and Mercator. Significant persistent temperature and salinity biases have also been highlighted in the intermediate and deep layers, especially in MFS which is colder and saltier than observations.

The sub-basin and local scale analyses have highlighted:

- The regional observed variability of the sea surface features and vertical hydrographic structures, as well as regional differences between simulations and observations.

- In the Alboran Sea, which has the most intense observed mesoscale activity, simulation biases have been highlighted. Although MFS better reproduces the main observed modes of sea level anomaly variability than Mercator, both simulations fail to properly represent the seasonal existence of the main gyres which govern the circulation in the Alboran Sea.

- Concerning the water mass characteristics, MFS does not properly represent the maxima of temperature of Levantine Intermediate Water in the western Mediterranean Sea. Additionally, in the Ibiza Channel, where meridional water mass exchanges occur between the north and south WMED, the observed Winter Intermediate Water is not present during winter 2011 in MFS, probably due to the ocean circulation bias, which has been revealed in this area. Although Mercator also has regional circulation biases, this simulation is able to reproduce the presence of Winter Intermediate Water in the Ibiza Channel.

Although observational data are assimilated in both ocean model systems, persistent biases have been highlighted in the ocean surface features as well as the three-dimensional ocean structure at basin, sub-basin and local scales. The simulation biases may be due to the initial state (especially in the deep layer where historical observation data are rare), the atmospheric forcings and air-sea flux uncertainties, the river runoff approximations, and the model errors induced by unresolved or parameterized physical processes. The improvement of the numerical simulations could be carried out:

- Based on sensitivity tests on the model parameters (atmospheric forcings, parameterizations of unresolved processes, numerical schemes),

- Studying and assimilating new types of observations in the systems (high resolution ocean surface topography, high resolution sea surface temperature, ocean colour, sea surface salinity, drifters, and gliders) to better constrain the modelled variables and to overcome the deficiencies of the background errors in particular for extrapolated and/or poorly observed variables,

- Assimilating observations specially tailored for assimilation systems (e.g. sea level anomaly products, Dobricic et al., 2012),

- Applying the multi-platform and multi-scale (basin, regional, local) validation approach to a longer simulation period,

- Extending the analyses to the whole Mediterranean Sea to understand the origin of some of the simulation biases (e.g. the Levantine Intermediate Water which is formed in the eastern basin),

- Extending the validation procedures to other datasets (e.g. drifters, chlorophyll, fixed moorings), 
- Investigating the ocean dynamics at various spatial and temporal scales (study of long-term variability, interactions between the small and large spatial and temporal scales, ocean physical processes, specific atmospheric and oceanic events), taking advantage of the wide spatiotemporal scale range of observational and numerical data;

with the necessary condition of the progressive extension and the durability of long-term observational data in both surface and deep ocean, the routine monitoring of specific areas using high resolution sampling platforms (e.g. gliders in the Ibiza Channel, the Strait of Sardinia), and the increase of numerical experiments.

\section{Acknowledgements}

We gratefully acknowledge the two anonymous reviewers for their relevant suggestions leading to the improvement of the paper. The study has been conducted using MyOcean Products (http://www.myocean.eu) from the Mediterranean Monitoring and Forecasting Centre, which has performed the Mediterranean Forecasting System, and from CNR-ISAC which provides optimally interpolated sea surface temperature products. The French Operational Oceanography Center, Mercator-Océan, is also acknowledged for having developed and provided the simulation PSY2V4R4. The altimetric products are produced by SSALTO/DUACS and distributed by AVISO (http://www.aviso.oceanobs.com). The Argo floats, XBTs and CTDs data are gathered, quality controlled and provided by the ENACT-ENSEMBLES project. We thank ENSTA, LOCEAN, OOV-LOV and the MOOSE observatory for collecting glider data in the north-western Mediterranean Sea. Partial support from JERICO, GROOM EU and MyOcean funded projects for the deployment of gliders in the Ibiza Channel is acknowledged as well as the IMEDEA and SOCIB technicians. Thanks are also given to Bartolome Garau, Emma Heslop and the SOCIB data center for the processing of these data. Finally, we acknowledge Romain Escudier for his valuable help in improving the figures and John Allen for revising the English.

\section{Glossary}

AJ Atlantic Jet

AW Atlantic Water

BC Balearic Current

DW Deep Water

EAG Eastern Alboran Gyre

EKE Eddy Kinetic Energy

EOF Empirical Orthogonal Function

KE Kinetic Energy

LIW Levantine Intermediate Water

ME Mean Error

MFS Mediterranean Forecasting System

NC Northern Current

RMSD Root Mean Square Difference

SLA Sea Level Anomaly 
SST Sea Surface Temperature

WAG Western Alboran Gyre

WIW Winter Intermediate Water

WMDW Western Mediterranean Deep Water

WMED Western Mediterranean Sea (as defined in this study)

\section{Appendix}

Let $O(x, y, t)$ and $M(x, y, t)$ be the observed (reference) and simulated (MFS or Mercator) data, respectively, in the geographic and temporal space $(x, y, t) . \bar{O}(x, y)$ and $\bar{M}(x, y)$ are the temporal means. The statistical metrics used in Section 5 are calculated based on daily time series over the period of time $\mathrm{T}$ and expressed as follow:

Standard deviation: $\sigma_{O}(x, y)=\sqrt{\frac{1}{T} \sum_{t=1}^{T}[O(x, y, t)-\bar{O}(x, y)]^{2}}$

$$
\sigma_{M}(x, y)=\sqrt{\frac{1}{T} \sum_{t=1}^{T}[M(x, y, t)-\bar{M}(x, y)]^{2}}
$$

Mean error: $\operatorname{ME}(x, y)=\bar{M}(x, y)-\bar{O}(x, y)$

Root mean square difference: $\operatorname{RMSD}(x, y)=\sqrt{\frac{1}{T} \sum_{t=1}^{T}[M(x, y, t)-O(x, y, t)]^{2}}$

\section{References}

Adani, M., S. Dobricic, and N. Pinardi (2011), Quality Assessment of a 1985-2007 Mediterranean Sea Reanalysis, J. Atmos. Ocean. Technol., 28, 569-589, doi:0.1175/2010JTECHO798.1.

Astraldi, M., S. Balopoulos, J. Candela, J. Font, M. Gacic, G. P. Gasparini, B. Manca, A. Theocharis, and J. Tintoré (1999), The role of straits and channels in understanding the characteristics of Mediterranean circulation, Prog. Oceanogr., 44, 65-108.

Bakun, A., and V.N. Agostini (2001), Seasonal patterns of wind-induced upwelling/downwelling in the Mediterranean Sea, Sci. Mar., 65(3), 243-257.

Baldacci, A., G. Corsini, R. Grasso, G. Manzella, J.T. Allen, P. Cipollini, T.H. Guymer, and H.M. Snaith (2001), A study of the Alboran sea mesoscale system by means of empirical orthogonal function decomposition of satellite data, J. Mar. Syst., 29, 1-4, 293-311, doi:10.1016/S09247963(01)00021-5.

Ben Ismail, S., C. Sammari, G.P. Gasparini, K. Béranger, M. Brahim, and L. Aleya (2012), Water masses exchanged through the Channel of Sicily: Evidence for the presence of new water masses on the Tunisian side of the Channel, Deep Sea Res., Part I, 63, 65-81, doi:10.1016/j.dsr.2011.12.009.

Bouffard J., S. Vignudelli, M. Hermann, F. Lyard, P. Marsaleix, Y. Ménard, and P. Cipollini (2008), Comparison of Ocean Dynamics with a Regional Circulation Model and Improved 
Altimetry in the North-Western Mediterranean, Terr. Atmos. Ocean. Sci., Vol. 19, No. 1-2, 117133, doi:10.3319/TAO.2008.19.1-2.117(SA).

Bouffard, J., L. Renault, S. Ruiz, A. Pascual, C. Dufau, and J. Tintoré (2012), Sub-surface smallscale eddy dynamics from multi-sensor observations and modeling, Prog. Oceanogr., 106, 62-79.

Buongiorno Nardelli, B., C. Tronconi, A. Pisano, and R. Santoleri (2013), High and Ultra-High resolution processing of satellite Sea Surface Temperature data over Southern European Seas in the framework of MyOcean project, Rem. Sens. Env., 129, 1-16, doi:10.1016/j.rse.2012.10.012.

Cailleau, S., J. Chanut, J.-M. Lellouche, B. Levier, C. Maraldi, G. Reffray, and M.G. Sotillo (2012), Towards a regional ocean forecasting system for the IBI (Iberia-Biscay-Ireland area): developments and improvements within the ECOOP project framework, Ocean Sci., 8, 143-159, doi:10.5194/os8-143-2012.

Cazenave, A., P. Bonnefond, F. Mercier, K. Dominh, and V. Toumazou (2002), Sea level variations in the Mediterranean Sea and Black Sea from satellite altimetry and tide gauges, Global and Planetary Change, 34, 1-2, 59-86, doi:10.1016/S0921-8181(02)00106-6.

Dai, A., and K.E. Trenberth (2002), Estimates of Freshwater Discharge from Continents: Latitudinal and Seasonal Variations, J. Hydrometeor., 3, 660-687, doi: http://dx.doi.org/10.1175/1525-7541(2002)003<0660:EOFDFC>2.0.CO;2.

Demirov, E., and N. Pinardi (2002), Simulation of the Mediterranean Sea circulation from 1979 to 1993: Part I. The interannual variability, J. Mar. Syst., 33-34, 23-50.

Dobricic, S., and N. Pinardi (2008), An oceanographic three-dimensional variational data assimilation scheme, Ocean Modell., 22, 89-105.

Dobricic, S., C. Dufau, P. Oddo, N. Pinardi, I. Pujol, and M.-H. Rio (2012), Assimilation of SLA along track observations in the Mediterranean with an oceanographic model forced by atmospheric pressure, Ocean Sci., 8, 787-795.

Drevillon, M., R. Bourdallé-Badie, C. Derval, J.-M. Lellouche, E. Remy, B. Tranchant, M. Benkiran, E. Greiner, S. Guinehut, N. Verbrugge, G. Garric, C.E. Testut, M. Laborie, L. Nouel, P. Bahurel, C. Bricaud, L. Crosnier, E. Dombrowsky, E. Durand, N. Ferry, F. Hernandez, O. Le Galloudec, F. Messal, and L. Parent (2008), The GODAE/Mercator- Ocean global ocean forecasting system: results, applications and prospects, J. Operational Oceanogr., 1, 51-57.

Estournel, C., X. Durrieu de Madron, P. Marsaleix, F. Auclair, C. Julliand, and R. Vehil (2003), Observations and modeling of the winter coastal oceanic circulation in the Gulf of Lion under wind conditions influenced by the continental orography (FETCH experiment), J. Geophys. Res., 108 (C3), 8059, doi:10.1029/2001JC000825.

Font, J., J. Salat, and J. Tintoré (1988), Permanent features of the circulation in the Catalan Sea, in Pelagic Mediterranean Oceanogr., edited by H.J. Minas and P. Nival, Oceanologica Acta, vol. 9, 51-57.

Good, S.A., M.J. Martin, and N.A. Rayner (2013), EN4: quality controlled ocean temperature and salinity profiles and monthly objective analyses with uncertainty estimates, J. Geophys. Res.: Oceans, 118, 6704-6716, doi:10.1002/2013JC009067. 
Greatbatch, R. J. (1994), A note on the representation of steric sea level in models that conserve volume rather than mass, J. Geophys. Res.: Oceans, 99(C6), 12767-12771, doi:10.1029/94JC00847.

Guihou, K., J. Marmain, Y. Ourmières, A. Molcard, B. Zakardjian, and P. Forget (2013), A case study of the mesoscale dynamics in the North-Western Mediterranean Sea: a combined data-model approach, Ocean Dyn., 63, 793-808, doi:10.1007/s10236-013-0619-z.

Herrmann, M., F. Sevault, J. Beuvier, and S. Somot (2010), What induced the exceptional 2005 convection event in the northwestern Mediterranean basin? Answers from a modeling study, $J$. Geophys. Res., 115, C12051, doi:10.1029/2010JC006162.

Heslop, E., S. Ruiz, J. Allen, J.L. López-Jurado, L. Renault, and J. Tintoré (2012), Autonomous underwater gliders monitoring variability at "choke points" in our ocean system: A case study in the Western Mediterranean Sea, Geophys. Res. Lett., 39, L20604, doi:10.1029/2012GL053717.

Juza, M., L. Renault, S. Ruiz, and J. Tintoré (2013), Origin and pathways of Winter Intermediate Water in the Northwestern Mediterranean Sea using observations and numerical simulation, $J$. Geophys. Res.: Oceans, 118, 1-13, doi:10.1002/2013JC009231.

Juza, M., B. Mourre, L. Renault, S. Gómara, K. Sebastián, S. Lora, J.P. Beltran, B. Frontera, B. Garau, C. Troupin, M. Torner, E. Heslop, B. Casas, G. Vizoso, and J. Tintoré (2015), Operational SOCIB forecasting system and multi-platform validation in the western Mediterranean Sea, submitted to J. Operational Oceanogr., Special Issue "Proceedings of the 3rd Italian GNOO Conference on operational oceanography, innovative technologies and applications".

Korres, G., and A. Lascaratos (2003), An eddy resolving model of the Aegean and Levantine basins for the Mediterranean Forecasting System Pilot Project (MFSPP): Implementation and climatological runs, Ann. Geophys., 21, 205-220.

Large, W.G., and S.G. Yeager (2009), The global climatology of an interannually varying air-sea flux data set, Clim. Dyn., 33, 341-364, doi:10.1007/s00382-008-0441-3.

Lellouche, J.M., O. Le Galloudec, M. Drevillon, C. Régnier, E. Greiner, G. Garric, N. Ferry, C. Desportes, C.-E. Testut, C. Bricaud, R. Bourdallé-Badie, B. Tranchant, M. Benkiran, Y. Drillet, A. Daudin, and C. De Nicola (2013), Evaluation of global monitoring and forecasting systems at Mercator Océan, Ocean Sci., 9, 57-81, doi:10.5194/os-9-57-2013.

López García, M.J., and A.M. Camarasa Belmonte (2011), Recent trends of SST in the Western Mediterranean basins from AVHRR Pathfinder data (1985-2007), Global and Planetary Change, 78, 127-136, doi:10.1016/j.gloplacha.2011.06.001.

Madec G. (2008), NEMO Ocean General Circulation Model Reference Manuel. Internal Report. LODYC/IPSL, Paris.

Malanotte-Rizzoli, P., J. Font, E. Garcia-Ladona, A. Pascual, J. Tintoré, and G. Triantafyllou (2014), Physical forcing and physical/biochemical variability of the Mediterranean Sea: a review of unresolved issues and directions for future research, Ocean Sci., 10, 281-322, doi:10.5194/os-10281-2014.

Manca, B., M. Burca, A. Giorgetti, C. Coatanoan, M.-J. Garcia, and A. Ion (2004), Physical and biochemical averaged vertical profiles in the Mediterranean regions: an important tool to trace the 
737 climatology of water masses and to validate incoming data from operational oceanography, J. Mar. 738 Syst., 48, 83-116, doi:10.1016/j.jmarsys.2003.11.025.

739 Marullo, S., B. Buongiorno Nardelli, M. Guarracino, and R. Santoleri (2007), Observing the 740 Mediterranean Sea from space: 21 years of Pathfinder-AVHRR sea surface temperatures (1985 to 741 2005): re-analysis and validation, Ocean Sci., 3.2, 299-310.

742 Millot, C. (1999), Circulation in the Western Mediterranean Sea, J. Mar. Syst., 20, 423-442.

743 Millot, C., and I. Taupier-Letage (2005), Circulation in the Mediterranean Sea, In The 744 Mediterranean Sea, pp. 29-66, Springer, Berlin Heidelberg.

745 Millot, C. (2013), Levantine intermediate water characteristics: An astounding general 746 misunderstanding!, Sci. Mar., 77(2), 217-232, doi:10.3989/scimar.03518.13A.

747 Oddo, P., N. Pinardi, and M. Zavatarelli (2005), A numerical study of the interannual variability of 748 the Adriatic Sea, Sci. Total Environment, 353, 39-56.

749 Oddo, P., M. Adani, N. Pinardi, C. Fratianni, M. Tonani, and D. Pettenuzzo (2009), A nested 750 Atlantic-Mediterranean Sea general circulation model for operational forecasting, Ocean Sci., 5, 751 461-473, doi:10.5194/os-5-461-2009.

752 Olita, A., S. Dobricic, A. Ribotti, L. Fazioli, A. Cucco, C. Dufau, and R. Sorgente (2012), Impact of 753 SLA assimilation in the Sicily Channel Regional Model: model skills and mesoscale features, 754 Ocean Sci., 8, 485-496, doi:10.5194/os-8-485-2012.

755 Pascual, A., E. Vidal-Vijande, S. Ruiz, S. Somot, and V. Papadopoulos (2014), Spatio-temporal 756 variability of the surface circulation in the Western Mediterranean: a comparative study using 757 altimetry and modeling, The Mediterranean Sea: Temporal Variability and Spatial Patterns, Ed.: 758 G.L. EusebiBorzelli, M. Gacic, P. Lionello, P. Malanotte-Rizzoli, American Geophysical Union.

759 Pinardi, N., M. Zavatarelli, M. Adani, G. Coppini, C. Fratianni, P. Oddo, S. Simoncelli, M. Tonani, 760 V.Lyubartsev, S. Dobricic, and A. Bonaduce (2013), Mediterranean Sea large-scale low-frequency 761 ocean variability and water mass formation rates from 1987 to 2007: A retrospective analysis, Prog. 762 Oceanogr., doi:10.1016/j.pocean.2013.11.003.

763 Pinot, J.-M., J. Tintoré, and D. Gomis (1995), Multivariate analysis of the surface circulation in the 764 Balearic Sea, Prog. Oceanogr., 36, 343-376.

765 Pinot, J.-M., and A. Ganachaud (1999), The role of Winter Intermediate Waters in the spring766 summer circulation of the Balearic Sea. Part 1. Hydrography and inverse modelling, J. Geophys. 767 Res., 104, 29843-29864.

768 Pinot, J.-M., J.L. López-Jurado, and M. Riera (2002), The CANALES experiment (1996769 1998).Interannual, seasonal, and mesoscale variability of the circulation in the Balearic Channels, 770 Prog. Oceanogr., 55, 335-370.

771 Renault, L., T. Oguz, A. Pascual, G. Vizoso, and J. Tintoré (2012), Surface circulation in the 772 Alboran Sea (western Mediterranean) inferred from remotely sensed data, J. Geophys. Res., 117, 773 C08009, doi:10.1029/2011JC007659. 
803

804

805

806

807

808
Renault, L., J. Chiggiato, J.C. Warner, M. Gomez, G. Vizoso, and J. Tintoré (2012), Coupled atmosphere-ocean-wave simulations of a storm event over the Gulf of Lion and Balearic Sea, $J$. Geophys. Res., 117(C9).

Robinson, A.R., W.G. Leslie, A. Theocharis, and A. Lascaratos (2001), Encyclopedia of Ocean Sciences, vol. 3, chap. Mediterranean Sea Circulation, pp. 1689-1705, Academic, London, doi:10.1006/rwos.2001.0376.

Tintoré, J., P.E. La Violette, I. Blade, and A. Cruzado (1988), A Study of an Intense Density Front in the Eastern Alboran Sea: The Almeria-Oran Front, J. Phys. Oceanogr., 18, 1384-1397.

Tintoré, J., et al. (2013), SOCIB: The Balearic Islands coastal ocean observing and forecasting system responding to science, technology and society needs, Mar. Technol. Soc. J., 47(1), 101-117.

Tonani, M., N. Pinardi, S. Dobricic, I. Pujol, and C. Fratianni (2008), A high-resolution free-surface model of the Mediterranean Sea, Ocean Sci., 4, 1-14.

Tonani, M., N. Pinardi, C. Fratianni, J. Pistoia, S. Dobricic, S. Pensieri, M. de Alfonso, and K. Nittis (2009), Mediterranean Forecasting System: forecast and analysis assessment through skill scores, Ocean Sci., 5, 649-660, doi:10.5194/os-5-649-2009.

Tonani M., A. Teruzzi, G. Korres, N. Pinardi, A. Crise, M. Adani, P. Oddo, S. Dobricic, C. Fratianni, M. Drudi, S. Salon, A. Grandi, G. Girardi, V. Lyubartsev, and S. Marino (2014), The Mediterranean Monitoring and Forecasting Centre, a component of the MyOcean system,Proceedings of the Sixth International Conference on EuroGOOS 4-6 October 2011, Sopot, Poland, Edited by H. Dahlin, N.C. Fleming and S. E. Petersson. First published 2014.Eurogoos Publication no. 30.ISBN 978-91-974828-9-9.

Tranchant, B., C.E. Testut, N. Ferry, F.Birol, and P. Brasseur (2005), SAM2: The second generation of Mercator assimilation system, Proceeding of the 4th international Conference on EUROGOOS, pp. 650-655.

User Handbook Ssalto/Duacs: M(SLA) and M(ADT) Near-Real Time and Delayed-Time, SALPMU-P-EA-21065-CLS, edition 4.1, May 2014.

Vetrano A., E. Napolitano, R. Iacono, K. Schroeder, and G.P. Gasparini (2010), Tyrrhenian Sea circulation and water mass fluxes in spring 2004: Observations and model results, J. Geophys. Res.: Oceans, 115, C06023, doi:10.1029/2009JC005680.

Vidal-Vijande, E., A. Pascual, B. Barnier, J.-M. Molines, and J. Tintoré (2011), Analysis of a 44year hindcast for the Mediterranean Sea: comparison with altimetry and in situ observations, Scientia Marina, 75(1)71-86, doi:10.3989/scimar.2011.75n1071.

Viúdez, A., J.-M. Pinot, and R.L. Haney (1998), On the upper circulation in the Alboran Sea, J. Geophys. Res., 103, C10, 21653-21666. 


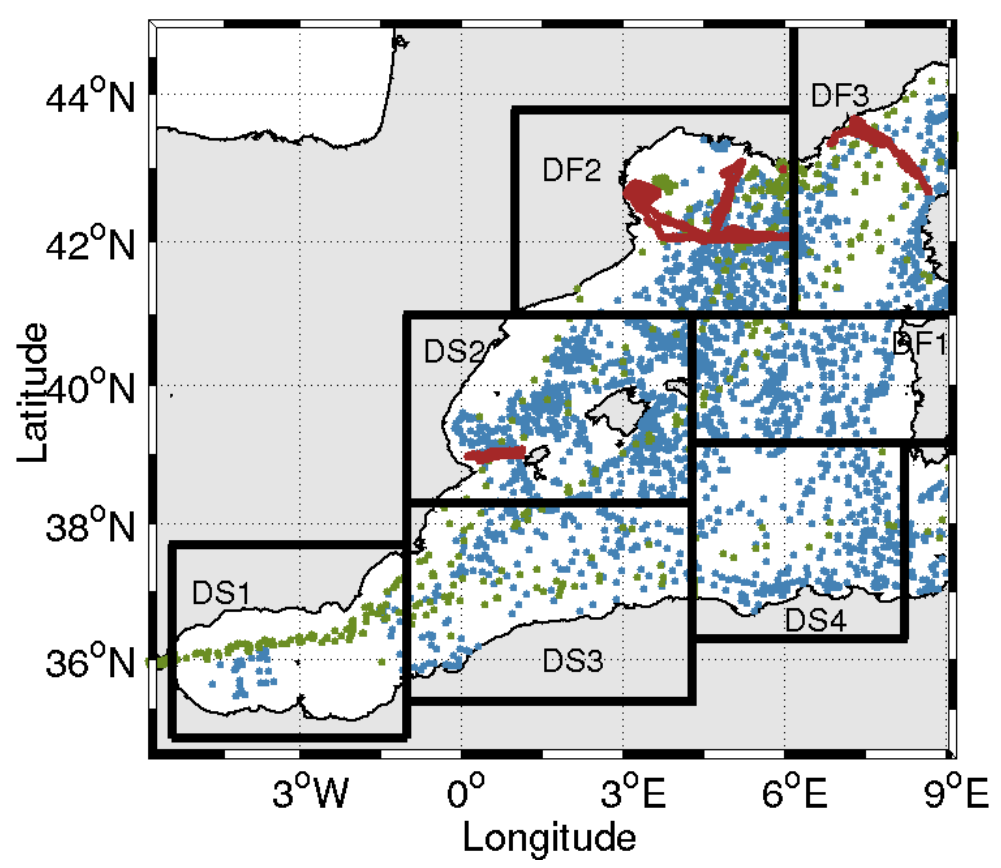

810 Fig. 1: Domain of study. The coloured points indicate the position of in situ hydrographic profiles 811 from Argo floats (blue) and XBTs (green) over the period 2009-2012, and glider sections (red) in 812 2011. The black boxes delimit the regions, as defined in Manca et al. (2004), in the western 813 Mediterranean Sea: Alboran Sea (DS1), Balearic Sea (DS2), western and eastern Algerian (DS3 and 814 DS4), Algero-Provençal (DF1), Liguro-Provençal (DF2) and Gulf of Lion (DF3). 


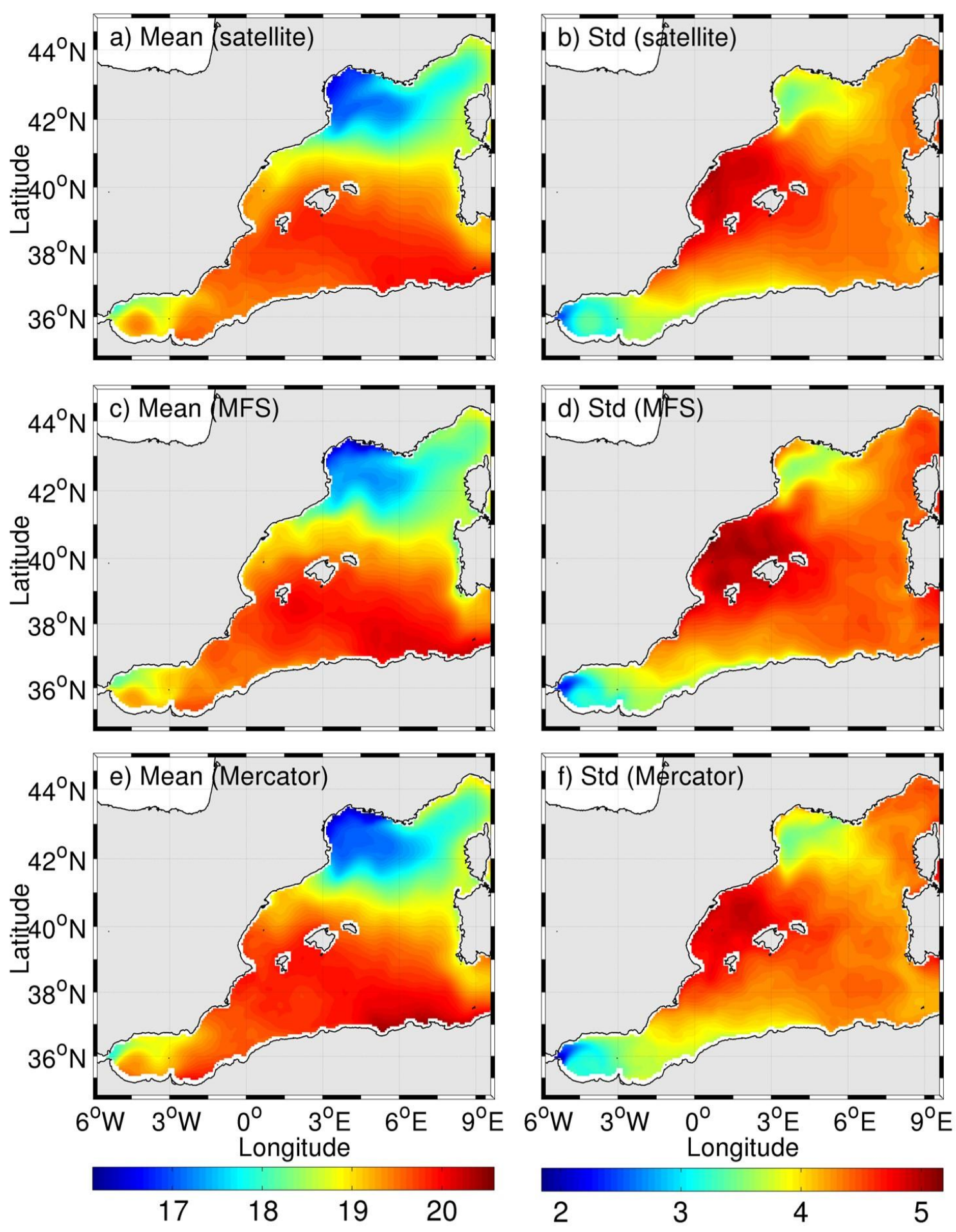

817 Fig. 2: Temporal means and standard deviations of SST (in ${ }^{\circ} \mathrm{C}$ ) over the 2009-2012 period for 818 satellite products (a,b), MFS (c,d) and Mercator (e,f). 

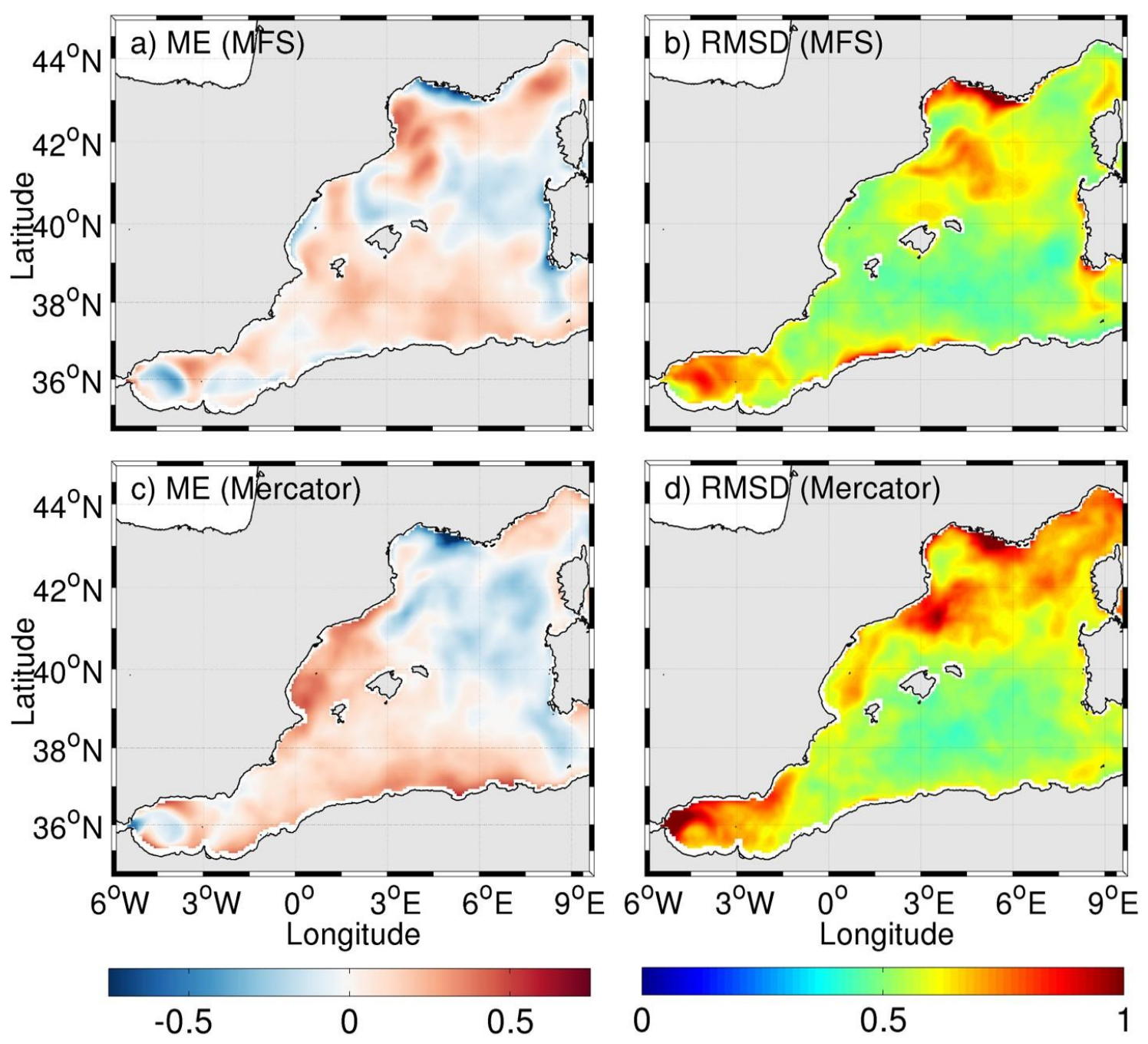

821 Fig. 3: SST mean error (ME) and root mean square difference (RMSD), as defined in the Appendix, 822 over the 2009-2012 period (in ${ }^{\circ} \mathrm{C}$ ) for MFS (a,b) and Mercator (c,d). 

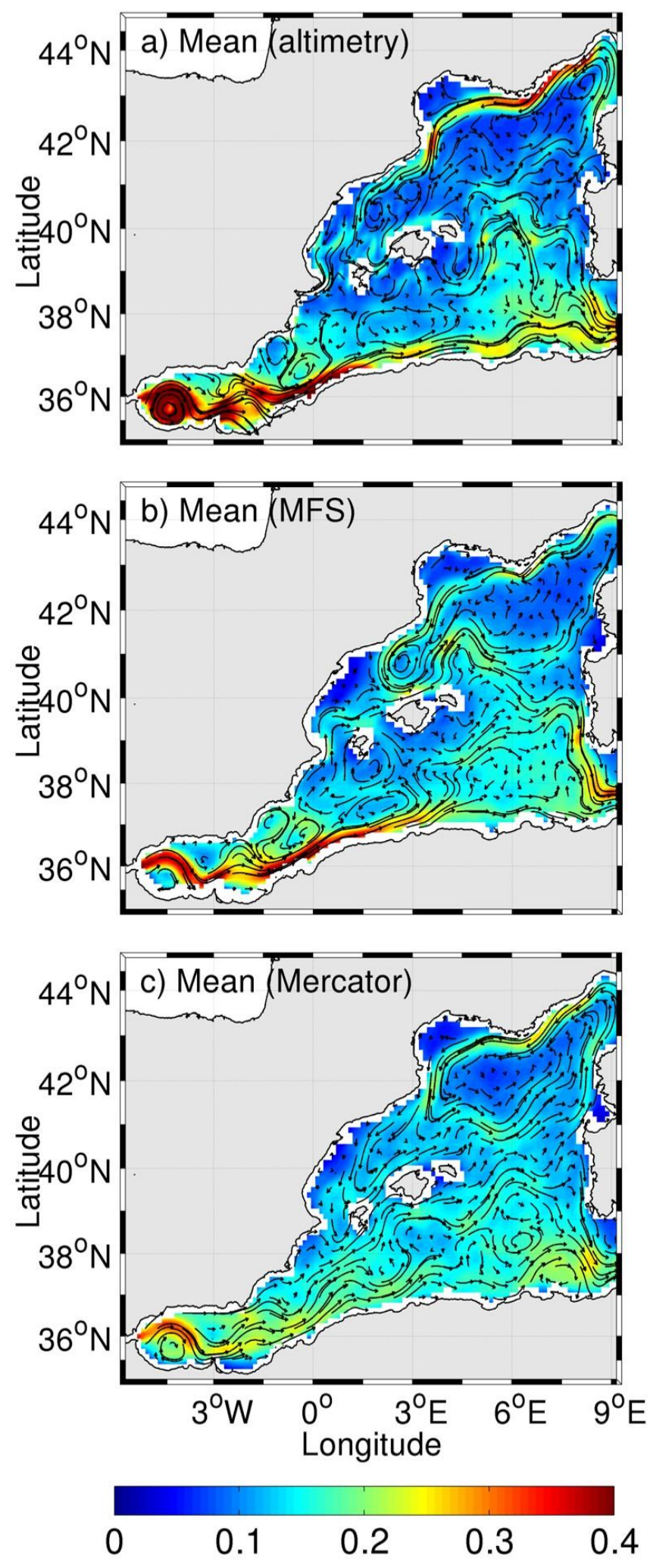

827 Fig. 4: Geostrophic currents (in $\mathrm{m} / \mathrm{s}$ ) averaged over the 2009-2012 period in the WMED from 828 satellite products (a), MFS (b) and Mercator (c). 

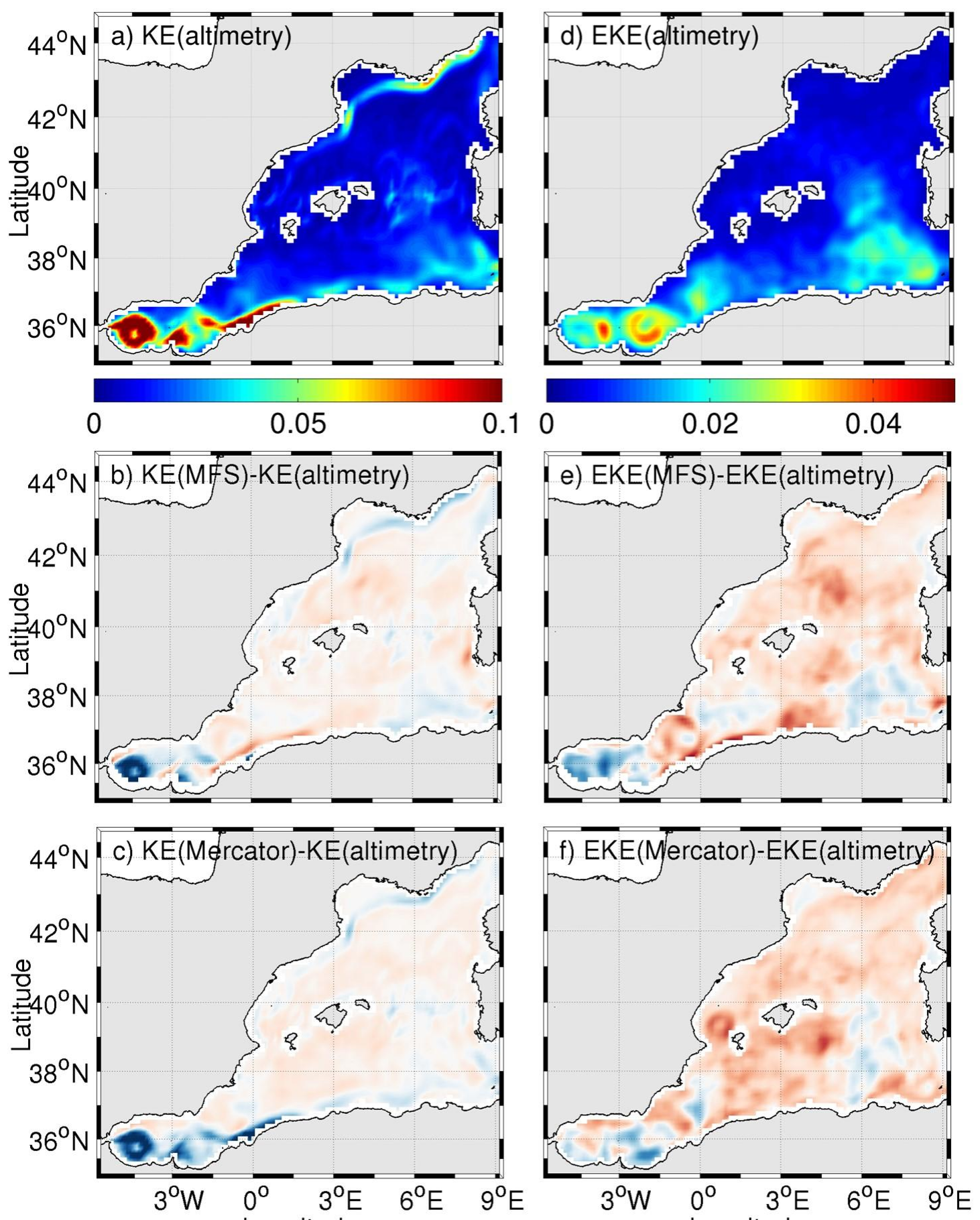

Longitude

830 Fig. 5: Mean observed kinetic energy (a) and mean error for MFS (b) and Mercator (c) over the $8312009-2012$ period (in $\mathrm{m}^{2} / \mathrm{s}^{2}$ ). Same for eddy kinetic energy (d,e,f). 

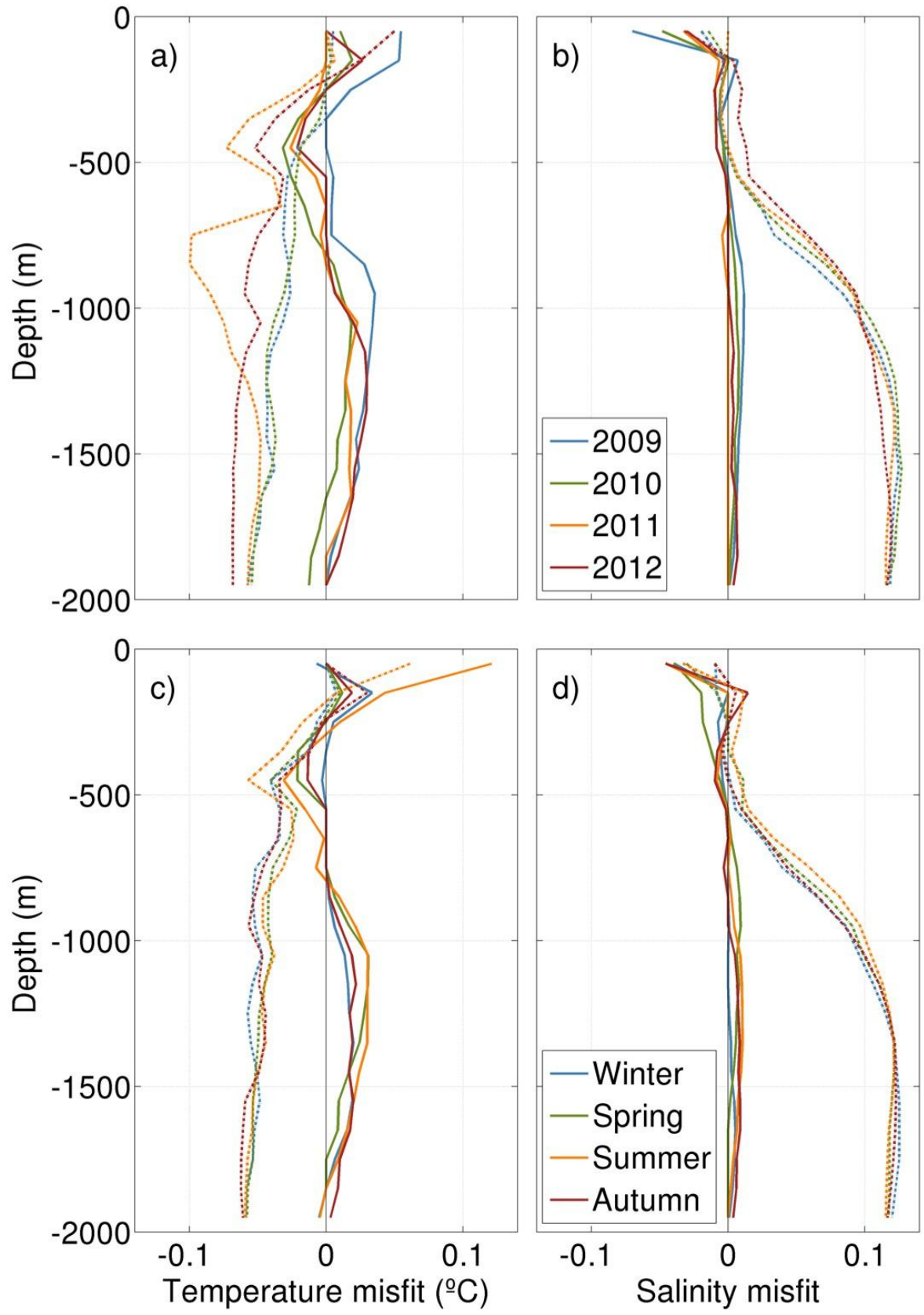

833 Fig. 6: Medians of the distributions of annual (a,b) and climatological seasonal (c,d) T and S misfits 834 (simulated minus observed values) as a function of depth over the 2009-2012 period for MFS 835 (dashed lines) and Mercator (solid lines). 

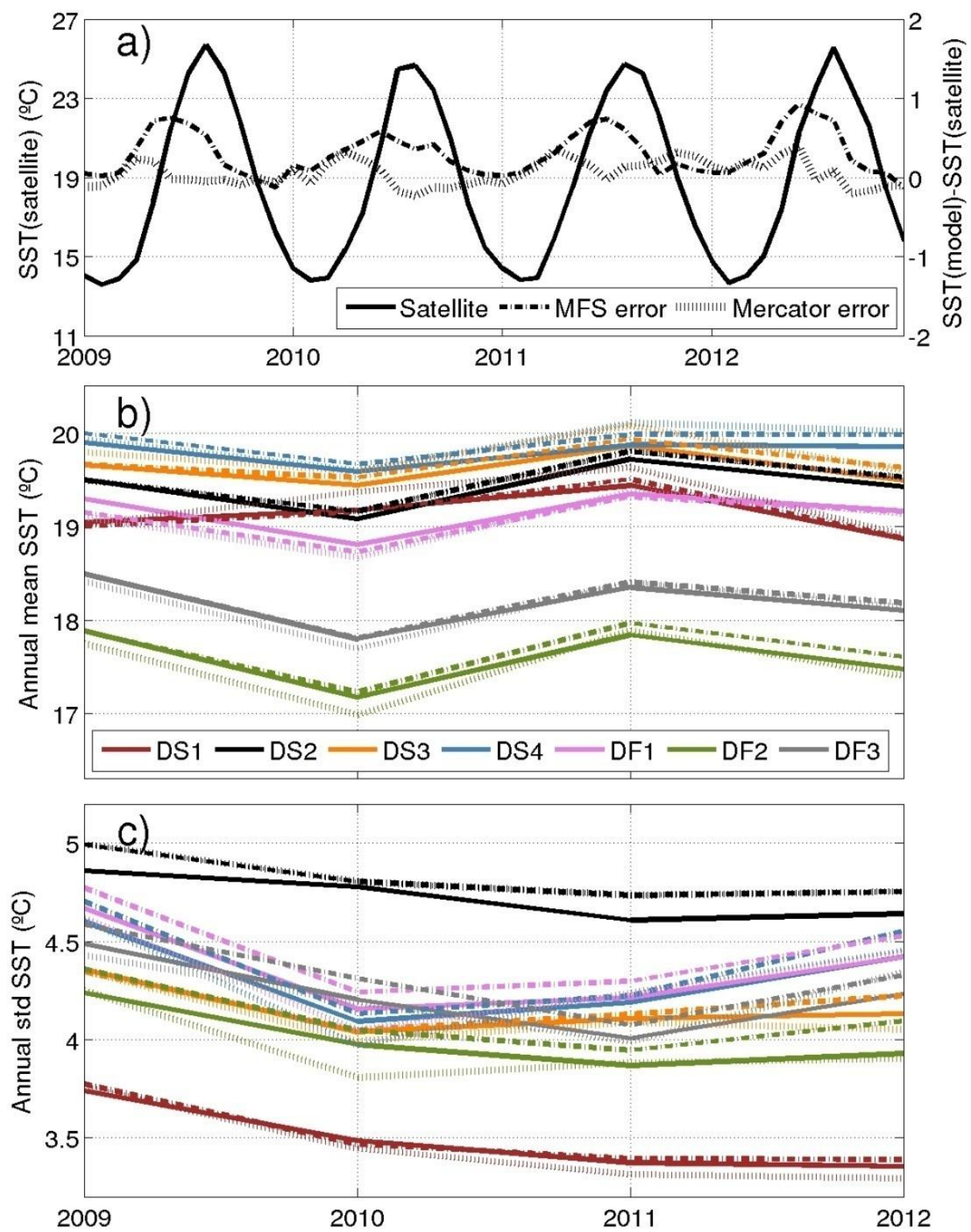

Fig. 7: Seasonal cycle of the monthly mean observed SST (in ${ }^{\circ} \mathrm{C}$ ) averaged in the WMED, and differences between the simulations and observations over the analysis period (a). Temporal mean (b) and standard deviation (c) of regional annual SST (in ${ }^{\circ} \mathrm{C}$ ) from 2009 to 2012 for observations (solid line), MFS (dashed line) and Mercator (dotted line): Alboran Sea (DS1), Balearic Sea (DS2),

843 west Algerian (DS3), east Algerian (DS4), Algero-Provençal (DF1), Gulf of Lion (DF2), Liguro-

844 Provençal (DF3). 

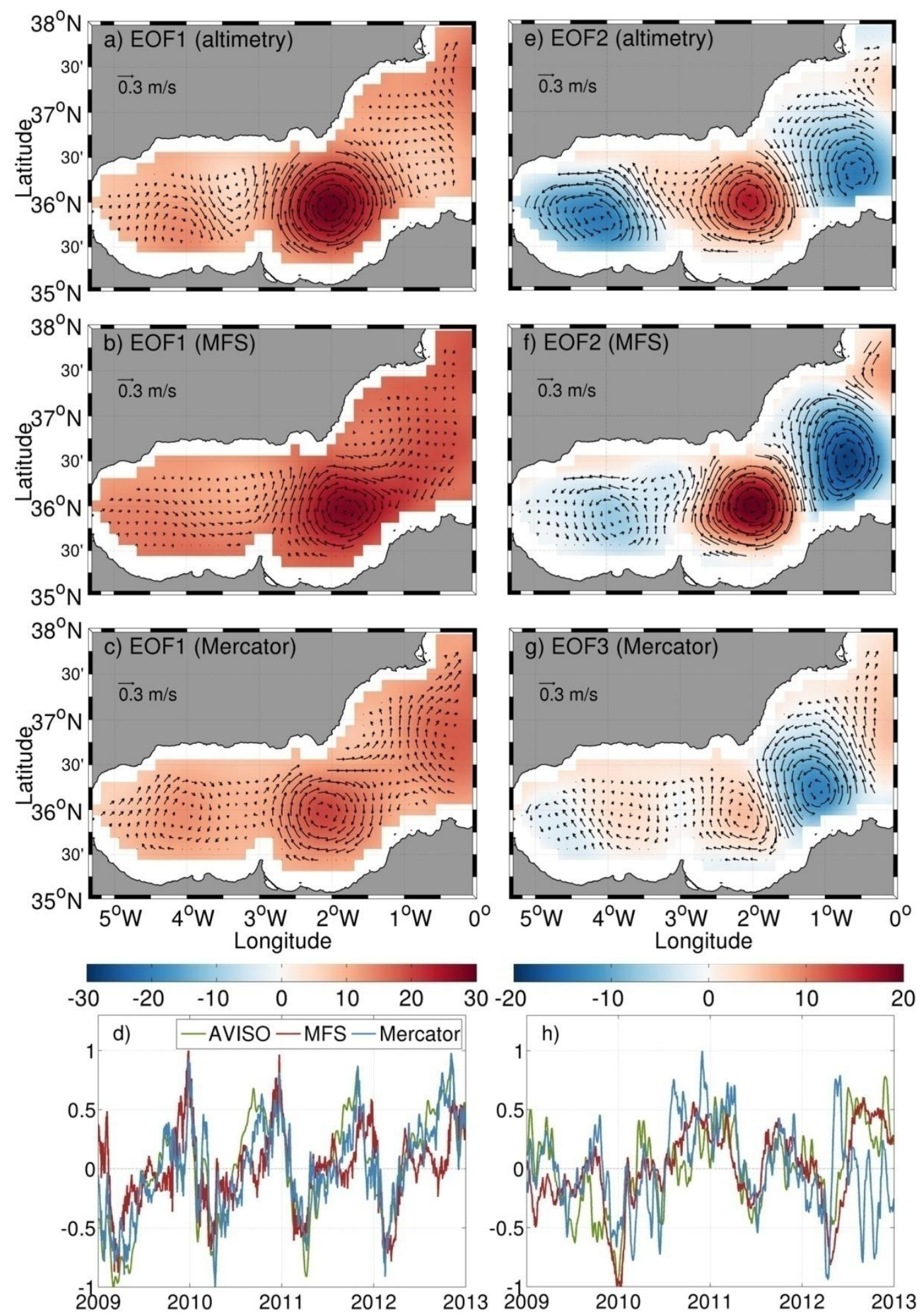

846 Fig. 8: First $(\mathrm{a}, \mathrm{b}, \mathrm{c})$ and second or third (e,f,g) modes of EOF analysis, and associated temporal 847 components $(\mathrm{d}, \mathrm{h})$, of observed and simulated sea level anomaly (in $\mathrm{cm}$ ) in the Alboran Sea over the 848 assessment period. Arrows indicate the associated geostrophic currents (in $\mathrm{m} / \mathrm{s}$ ). 

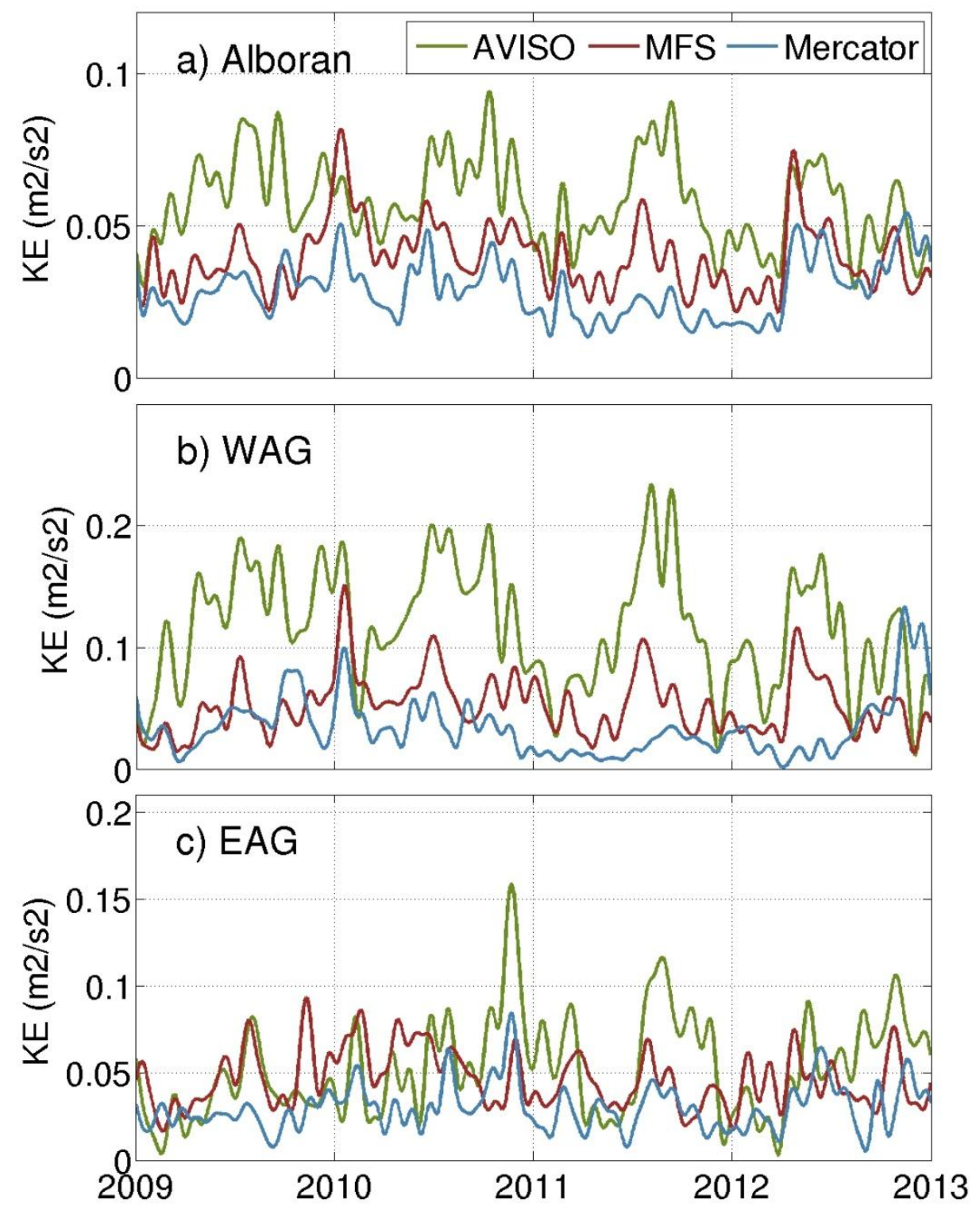

849

850 Fig. 9: Time series of observed and simulated kinetic energy (in $\mathrm{m}^{2} / \mathrm{s}^{2}$ ) averaged over the Alboran 851 Sea (a), and the WAG- and EAG-boxes (b and c, respectively) over the analysis period.

852

853

854 

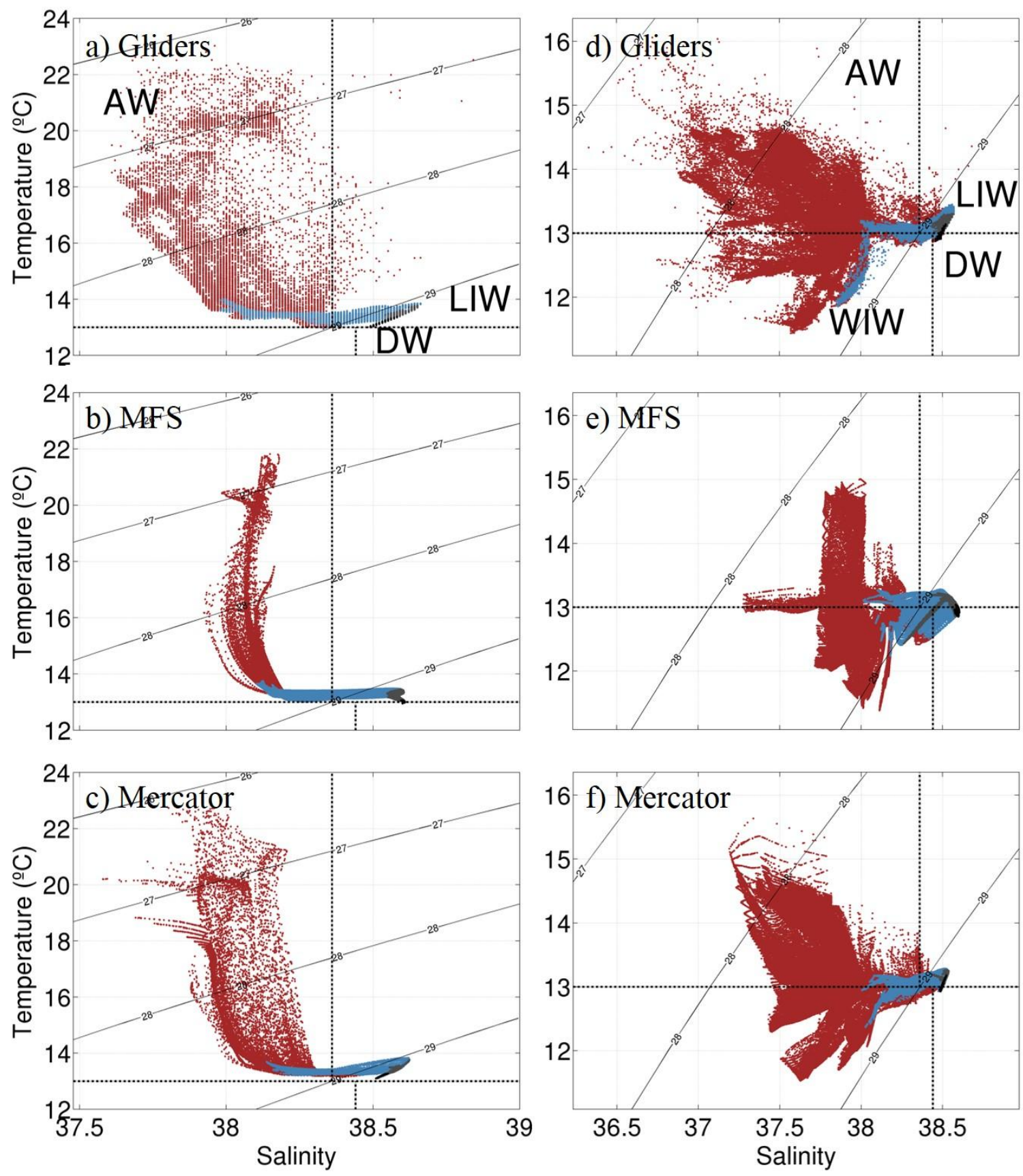

856 Fig. 10: Observed and simulated T/S diagrams during two gliders missions (from ENACT857 ENSEMBLES): western Ligurian Sea in May-June 2011 (a,b,c) and Gulf of Lion in March-April 8582011 (d,e,f). Colors indicate vertical layers: [0-100m] (red), [100-400m] (blue), [400-800m] (grey) 859 and [>800m] (black). Observed characteristic water masses are indicated: AW, LIW, WIW, and 860 DW. 

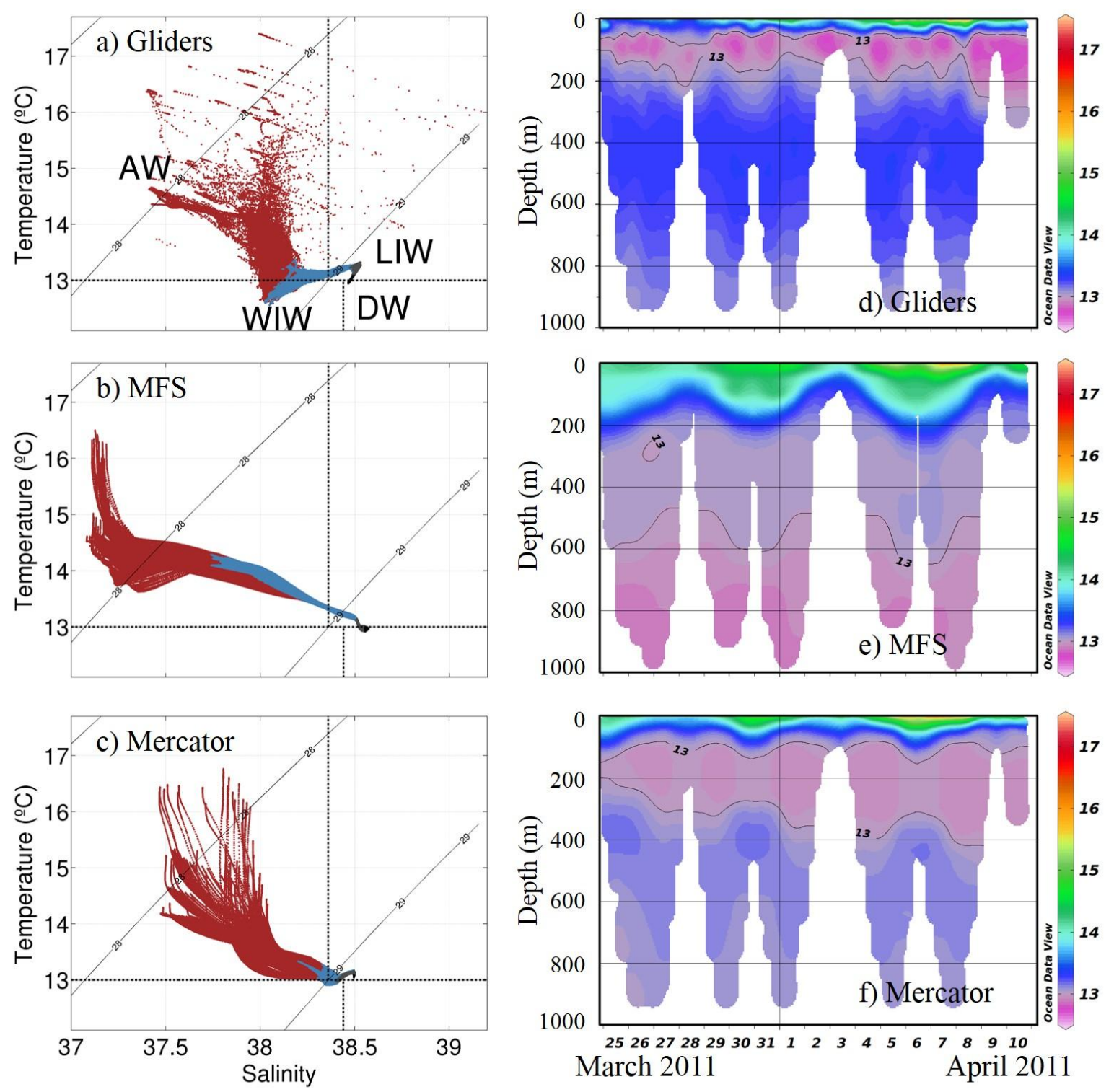

863 Fig. 11: Observed and simulated T/S diagrams (a,b,c) and associated vertical sections of 864 temperature (d,e,f) during the SOCIB glider mission in the Ibiza Channel in March-April 2011. 